\title{
The radiative role of ozone and water vapour in the annual temperature cycle in the tropical tropopause layer
}

\author{
Alison Ming ${ }^{1}$, Amanda C. Maycock ${ }^{2}$, Peter Hitchcock ${ }^{3}$, and Peter Haynes ${ }^{1}$ \\ ${ }^{1}$ Department of Applied Mathematics and Theoretical Physics, University of Cambridge, Cambridge, UK \\ ${ }^{2}$ School of Earth and Environment, University of Leeds, Leeds, UK \\ ${ }^{3}$ National Center for Atmospheric Research, Boulder, Colorado, USA \\ Correspondence to: Alison Ming (a.ming@damtp.cam.ac.uk)
}

Received: 25 October 2016 - Discussion started: 22 November 2016

Revised: 7 April 2017 - Accepted: 13 April 2017 - Published: 8 May 2017

\begin{abstract}
The structure and amplitude of the radiative contributions of the annual cycles in ozone and water vapour to the prominent annual cycle in temperatures in the tropical tropopause layer (TTL) are considered. This is done initially through a seasonally evolving fixed dynamical heating (SEFDH) calculation. The annual cycle in ozone is found to drive significant temperature changes predominantly locally (in the vertical) and roughly in phase with the observed TTL annual cycle. In contrast, temperature changes driven by the annual cycle in water vapour are out of phase with the latter. The effects are weaker than those of ozone but still quantitatively significant, particularly near the cold point $(100$ to $90 \mathrm{hPa}$ ) where there are substantial non-local effects from variations in water vapour in lower layers of the TTL. The combined radiative heating effect of the annual cycles in ozone and water vapour maximizes above the cold point and is one factor contributing to the vertical structure of the amplitude of the annual cycle in lower-stratospheric temperatures, which has a relatively localized maximum around $70 \mathrm{hPa}$. Other important factors are identified here: radiative damping timescales, which are shown to maximize over a deep layer centred on the cold point; the vertical structure of the dynamical heating; and non-radiative processes in the upper troposphere that are inferred to impose a strong constraint on tropical temperature perturbations below $130 \mathrm{hPa}$. The latitudinal structure of the radiative contributions to the annual cycle in temperatures is found to be substantially modified when the SEFDH assumption is relaxed and the dynamical response, as represented by a zonally symmetric calculation, is taken into account. The effect of the dynamical response is to reduce the strong latitudinal gradients and inter-
\end{abstract}

hemispheric asymmetry seen in the purely radiative SEFDH temperature response, while leaving the $20^{\circ} \mathrm{N}-20^{\circ} \mathrm{S}$ average response relatively unchanged. The net contribution of the annual ozone and water vapour cycles to the peak-to-peak amplitude in the annual cycle of TTL temperatures is found to be around $35 \%$ of the observed $8 \mathrm{~K}$ at $70 \mathrm{hPa}, 40 \%$ of $6 \mathrm{~K}$ at $90 \mathrm{hPa}$, and $45 \%$ of $3 \mathrm{~K}$ at $100 \mathrm{hPa}$. The primary sensitivity of the calculated magnitude of the temperature response is identified as the assumed annual mean ozone mixing ratio in the TTL.

\section{Introduction}

The tropical tropopause layer (TTL), spanning from 150 to $70 \mathrm{hPa}$ or 14 to $18.5 \mathrm{~km}$, is the main entry region for air into the stratosphere from the troposphere (e.g. Fueglistaler et al., 2009). The properties of this region are influenced by the presence of a prominent annual cycle in temperatures which is clear in, for example, radiosonde measurements (Reed and Vlcek, 1969) and GPS radio occultation measurements (Randel et al., 2003). Figure 1 shows the structure of the annual temperature cycle in a month-by-month climatology from the ERA-Interim reanalysis dataset (Dee et al., 2011), constructed using data from 1991 to 2010. Consistent with earlier studies, the annual cycle in temperatures is coherent over the layer from 130 to $40 \mathrm{hPa}$ (Fig. 1a), with relatively cold temperatures in Northern Hemisphere (NH) winter, relatively warm temperatures in $\mathrm{NH}$ summer only and early autumn, and weak latitudinal gradients over the tropics $\left(20^{\circ} \mathrm{N}-20^{\circ} \mathrm{S}\right.$; Fig. 1b-d). The maximum peak-to-peak amplitude of the an- 

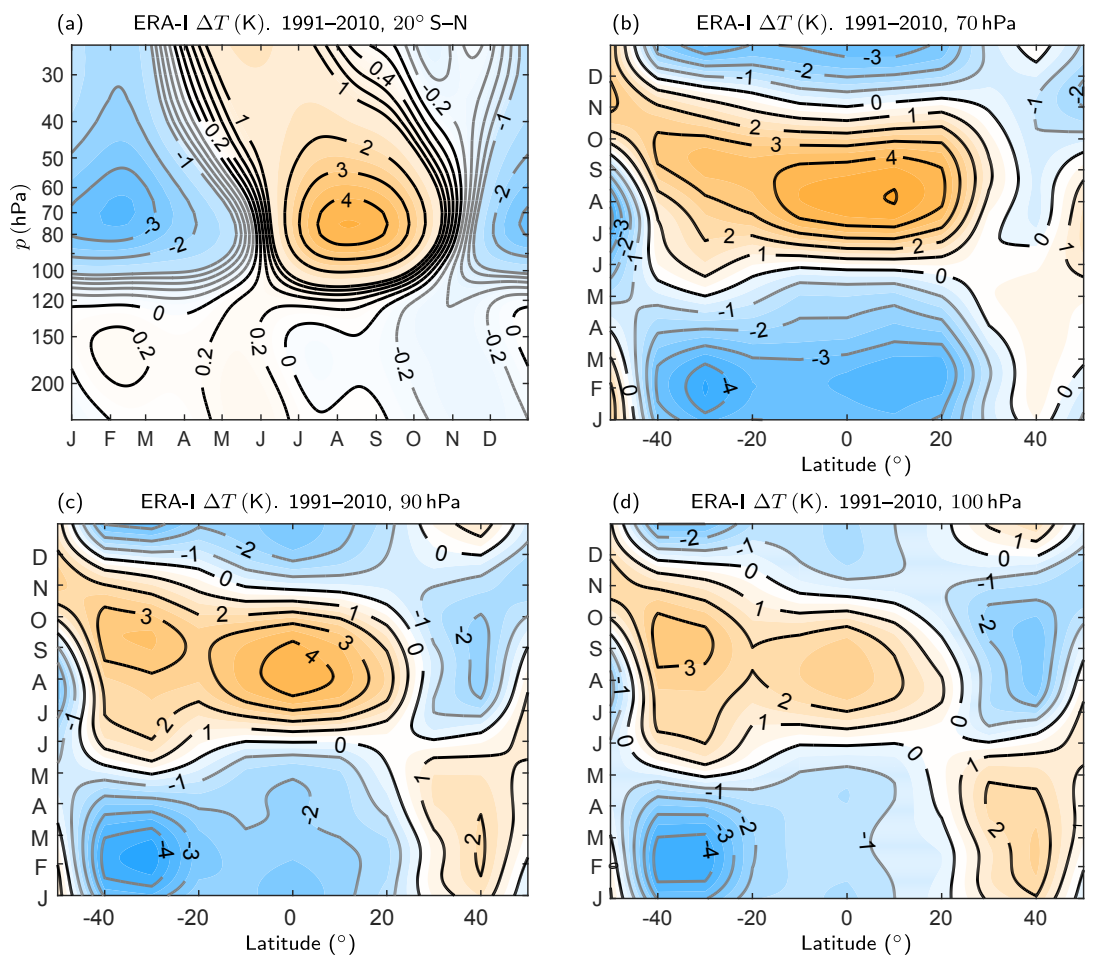

Figure 1. Climatology of the annual temperature cycle in ERA-Interim constructed by averaging from 1991 to 2010 : (a) between $20^{\circ} \mathrm{N}$ and $20^{\circ} \mathrm{S}$, (b) at $70 \mathrm{hPa}$, (c) at $90 \mathrm{hPa}$, and (d) at $100 \mathrm{hPa}$. The marks for the months indicate the first day of each month. The values of the temperature are shown by solid contours with contour values labelled explicitly. The coloured contours are shown at intervals equal to half of the solid contour interval. These conventions are followed in all of the figures in the paper.

nual cycle is $8 \mathrm{~K}$ near $70 \mathrm{hPa}$, decreasing to $6 \mathrm{~K}$ at $90 \mathrm{hPa}$ and $3 \mathrm{~K}$ at $100 \mathrm{hPa}$, below which the amplitude reduces very rapidly (Fig. 1a). Above about $30 \mathrm{hPa}$ (not shown), temperature variations are dominated by the semi-annual oscillation.

The temperature variations at the tropical cold point near 100 to $90 \mathrm{hPa}$ regulate the water vapour entering the stratosphere on annual and interannual timescales by modulating the freeze drying of upwelling air (e.g. Fueglistaler and Haynes, 2005; Fueglistaler et al., 2005; Randel and Jensen, 2013). In particular, the regular annual cycle in temperatures shown in Fig. 1c at $90 \mathrm{hPa}$ and panel (d) at $100 \mathrm{hPa}$ leads to a substantial annual cycle in water vapour. The additional effect of upward transport in the lower-stratospheric Brewer-Dobson circulation creates the well-known water vapour tape recorder signal (e.g. Mote et al., 1996; Randel et al., 2001). Note that the larger annual temperature cycle at $70 \mathrm{hPa}$ (Fig. 1b) does not have a direct effect on water vapour because overall temperatures are higher than at the cold point below.

Despite the potential significance of the annual cycle in TTL temperatures, both in its role in determining stratospheric water vapour mixing ratios and also simply as a conspicuous and persistent aspect of temperature variation, the mechanisms responsible for the cycle are not yet completely clear. Furthermore, state-of-the-art climate models, e.g. within the CMIP5 dataset, still exhibit large inter-model differences in the amplitude of the annual cycle at $100 \mathrm{hPa}$ with peak-to-peak amplitudes ranging from $\sim 1$ to $\sim 5 \mathrm{~K}$ compared to $\sim 4 \mathrm{~K}$ for the $15^{\circ} \mathrm{N}-\mathrm{S}$ average in ERA-Interim (Kim et al., 2013). This indicates that many current climate models do not capture correctly the processes that drive the TTL annual temperature cycle. Moreover, the lack of an understanding of the quantitative impact of different physical mechanisms on TTL temperatures precludes the development of a set of general principles for improving models (Hardiman et al., 2015).

To consider the annual cycle further, it is useful to begin by introducing the thermodynamic equation in the transformed Eulerian mean framework (Andrews et al., 1987), neglecting eddy terms:

$\partial_{t} \bar{T}=\bar{Q}_{\mathrm{rad}}-\bar{w}^{*} \bar{S}-\bar{v}^{*} \partial_{y} \bar{T}=\bar{Q}_{\mathrm{rad}}+\bar{Q}_{\mathrm{dyn}} ;$

this predicts the rate of change of zonal mean temperature, $\bar{T}$, with time, $t$, where $\overline{(.)}$ represents a zonal mean. The dynamical heating, $\bar{Q}_{\text {dyn }}$, is defined by the second equality in Eq. (1). $\bar{v}^{*}$ and $\bar{w}^{*}$ are the horizontal and vertical components of the mean residual velocity respectively. $y$ is the meridional coordinate. $\bar{S}=\partial_{z} \bar{T}+\kappa \bar{T} / H$ is a measure of the static stability, where $z$ is the $\log$-pressure height. $z=-H \log (\sigma)$, where $H$ is a scale height taken to be $7 \mathrm{~km}$, and $\sigma=p / p_{0}$, where $p$ 
is pressure and $p_{0}=1000 \mathrm{hPa} . \kappa=R / c_{p} \simeq 2 / 7$, where $R$ is the gas constant for dry air and $c_{p}$ is the specific heat at constant pressure. The radiative heating, $\bar{Q}_{\text {rad }}$, depends in general on the temperature and the distributions of various radiatively active components including clouds, aerosols, and trace gases.

Combined with the equations for zonal wind, continuity, and thermal wind balance, Eq. (1) determines the zonally symmetric response to imposed heatings and mechanical forcing (Andrews et al., 1987, Chap. 3). This is particularly important in considering the response to an imposed forcing on the right-hand side of Eq. (1) or indeed an imposed forcing term in one of the other equations.

Many studies have focused on the role of wave-induced forces in driving the annual cycle in temperature through their effects on upwelling in the TTL and hence on $\bar{Q}_{\text {dyn }}$ in Eq. (1), although uncertainty remains about what types of waves are the most important (Randel and Jensen, 2013, and references therein). However, radiative contributions to the annual cycle have also been suggested, principally in connection with the strong annual cycle in TTL ozone mixing ratios (Folkins et al., 2006; Randel et al., 2007). The quantitative effect of ozone on TTL temperatures was first investigated by Chae and Sherwood (2007), who used a one-dimensional radiative convective model representing a tropical average profile. They concluded that at $70 \mathrm{hPa}$, about $3 \mathrm{~K}$ of the observed $8 \mathrm{~K}$ peak-to-peak variation in temperature might be caused by the radiative effects of the annual cycle in ozone, reducing to about $1 \mathrm{~K}$ of the observed $3 \mathrm{~K}$ peak-to-peak variation at $100 \mathrm{hPa}$. Fueglistaler et al. (2011) used a seasonally evolving fixed dynamical heating (SEFDH; see Sect. 2) calculation and found a slightly smaller contribution from ozone of $2 \mathrm{~K}$ at $70 \mathrm{hPa}$.

Both Chae and Sherwood (2007) and Fueglistaler et al. (2011) asserted that annual variations in TTL water vapour mixing ratios only have a small role in determining the annual cycle in temperatures; quantitative details, however, were omitted. There has been recent significant interest in the radiative effect of variations in stratospheric water vapour, both in the effect on the radiative balance of the troposphere (e.g. Forster and Shine, 2002; Solomon et al., 2010) and also in the effect on the lower stratosphere. For example, Maycock et al. (2011) used a set of radiative calculations to show that a uniform increase in stratospheric water vapour gives rise to a cooling that is largest in the lower stratosphere at all latitudes.

In this work, we investigate, first using the SEFDH approach, the individual and combined radiative effects of the annual cycles in ozone and water vapour on TTL temperatures, including at $70 \mathrm{hPa}$ where the amplitude of the annual cycle is at a maximum and at $90 \mathrm{hPa}$ near the cold point which is crucial for determining stratospheric water vapour mixing ratios. The radiative calculations required for this investigation also allow us to examine carefully how vertical structure in the background radiative environment combines with the variations in radiative and dynamical heating to determine the vertical structure of the annual cycle in temperatures. All the calculations presented here neglect any cloud effects and assume clear-sky conditions.

For a more complete assessment of the effect of seasonal variations in ozone and water vapour on the annual cycle in TTL temperatures, which goes beyond the simplifying assumptions of the SEFDH approach, it is necessary to take account of dynamical changes. The seasonal cycle in radiative heating induced by ozone and water vapour variations will in part be balanced by a change in the meridional circulation (e.g. Plumb, 1982; Garcia, 1987; Haynes et al., 1991). This is shown in Sect. 5 below to modify strongly the latitudinal structure of the temperature response.

The structure of the paper is as follows. Section 2 describes the data and the radiative calculations. Section 3 describes the results of SEFDH calculations to quantify the effect of annual variations in ozone and water vapour on the annual cycle of temperature in the TTL. This section includes a detailed discussion of the radiative effects of water vapour variations omitted by previous authors. These calculations are complemented by a set of illustrative fixed dynamical heating $(\mathrm{FDH})$ radiative calculations in Appendix A. The SEFDH temperature changes are also sensitive to the background ozone mixing ratios and a set of further calculations is presented in Appendix C. (The results presented in Sect. 3 are in broad agreement with those from similar work by Gilford and Solomon (2017), which we became aware of during the review process.) Section 4 discusses the vertical structure of the annual cycle in temperature, distinguishing the role of the background radiative environment from that of the radiative and dynamical heating in determining this structure. Details regarding the estimates of uncertainty associated with the calculations in Sects. 3 and 4 are given in Appendix B. Section 5 then goes beyond the SEFDH calculation reported in Sect. 3 to consider how the temperature response to variations in ozone and water vapour is modified by the zonally symmetric dynamical response to the radiative heating. The final section discusses the results and their implications and reviews the various simplifying assumptions that have been made.

\section{Data and radiative method}

We use temperature and dynamical fields from the ERAInterim reanalysis dataset covering the period 1991 to 2010, using data at a horizontal resolution of $1^{\circ}$, at 6-hourly analysis time intervals (00:00, 00:06, 00:12, and 00:18 UTC) and at 60 model levels. The mean residual vertical velocity in the transformed Eulerian mean framework, calculated using the same method as Seviour et al. (2012), and the dynamical heating used in Sect. 4 are both computed on the original grid from the ERA-Interim data and then smoothed by lin- 
early interpolating the monthly averages to daily values. The temperatures are also linearly interpolated to the grids relevant for the calculations described below and in Sect. 5 .

Ozone and water vapour mixing ratios are obtained from the Stratospheric Water and OzOne Satellite Homogenized dataset (SWOOSH; Davis et al., 2016; Davis and Rosenlof, 2016; Tummon et al., 2015). This record is formed from a combination of measurements from various limb and solar occultation satellite instruments from 1984 to 2015, namely SAGE-II/III, UARS HALOE (Harries et al., 1996; Bruhl et al., 1996), UARS MLS, and Aura MLS (Lambert et al., 2007) instruments. The measurements are homogenized by applying corrections that are calculated from data taken during time periods of instrument overlap. Using the same data, SWOOSH also provides combined monthly climatologies of ozone and water vapour which we make use of in this work. SWOOSH is chosen for this study because it provides a homogenized record useful for climate studies and has been used previously to study both stratospheric water vapour (Maycock et al., 2014) and stratospheric ozone (Harris et al., 2015) variability. The pressure at the lowest altitude level in SWOOSH is $316 \mathrm{hPa}$. The results presented in this paper are not sensitive to mixing ratios of water vapour and ozone below $316 \mathrm{hPa}$ (within plausible limits), and for convenience the vertical profiles below $316 \mathrm{hPa}$ were simply defined by linear interpolation between the SWOOSH values at $316 \mathrm{hPa}$ and the surface values taken from ERA-Interim.

The radiative calculations were performed using a modified version of the Morcrette (1991) radiation scheme, which includes updates to the longwave absorption properties of water vapour (Zhong and Haigh, 1995). All calculations were performed on zonal mean data at $5^{\circ}$ intervals in latitude and at 100 pressure levels (which are the same as those listed in Appendix A for the FDH calculations). Shortwave heating rates are calculated as diurnal averages and the surface albedo is taken from ERA-Interim data. Carbon dioxide is assumed to be well mixed and the volume mixing ratio is set to 360 ppmv. All calculations in this study assume clear-sky conditions (i.e. neglecting radiative effects of clouds).

To study the radiative contributions of seasonal variations in ozone and water vapour to the annual cycle in TTL temperatures, we make use of the seasonally evolving fixed dynamical heating calculation (Forster et al., 1997). This method calculates the time-varying temperature change due to a specified radiative perturbation (e.g. a change in a trace gas) and takes into account the specified time dependence of temperature and trace gas concentration profiles in a background state to which the perturbation is applied.

Given time-varying background profiles (at a specified latitude) of temperatures, $\bar{T}^{0}$, and mixing ratios of trace gases, $\bar{\chi}_{\mathrm{O}_{3}}^{0}$ and $\bar{\chi}_{\mathrm{H}_{2} \mathrm{O}}^{0}$ (where $(\cdot)^{0}$ denotes the background state), the dynamical heating, $\bar{Q}_{\mathrm{dyn}}^{0}$, is first calculated by assuming the balance in Eq. (1), i.e. $\partial_{t} \bar{T}^{0}=\bar{Q}_{\mathrm{rad}}\left(\bar{T}^{0}, \bar{\chi}_{\mathrm{O}_{3}}^{0}, \bar{\chi}_{\mathrm{H}_{2} \mathrm{O}}^{0}\right)+\bar{Q}_{\mathrm{dyn}}^{0}$.

A perturbation is applied to the trace gas mixing ratios $\left(\Delta \bar{\chi}_{\mathrm{O}_{3}}, \Delta \bar{\chi}_{\mathrm{H}_{2} \mathrm{O}}\right)$, and the new time evolving equilibrium temperature state, $\bar{T}^{0}+\Delta \bar{T}$, is obtained from

$$
\begin{aligned}
\partial_{t}\left(\bar{T}^{0}+\Delta \bar{T}\right) & =\bar{Q}_{\mathrm{rad}}\left(\bar{T}^{0}+\Delta \bar{T}, \bar{\chi}_{\mathrm{O}_{3}}^{0}+\Delta \bar{\chi}_{\mathrm{O}_{3}}, \bar{\chi}_{\mathrm{H}_{2} \mathrm{O}}^{0}\right. \\
& \left.+\Delta \bar{\chi}_{\mathrm{H}_{2} \mathrm{O}}\right)+\bar{Q}_{\mathrm{dyn}}^{0} .
\end{aligned}
$$

Equation (3) is integrated forward in time with a daily time step until the perturbed temperature field, $\bar{T}^{0}+\Delta \bar{T}$, is also annually repeating. Five years is found to be sufficient for accurate convergence (see Appendix A for the criteria for convergence). The radiative transfer calculation couples vertical levels but not latitudes so that each calculation is local in latitude. Following a similar method to Forster et al. (1997), Eq. (3) is applied to update the temperature only above a certain level taken here to be $130 \mathrm{hPa}$, on the basis that there are distinct processes determining temperature variations in the troposphere below. The choice of this level is further justified in Sect. 4. In setting up the calculation we verified that the Forster et al. (1997) results could be reproduced. The SEFDH technique reduces to the more standard and widely used FDH technique if the imposed background temperature and species mixing ratios are constant in time and Eq. (3) is integrated to a steady state (Appendix A).

The background state is taken to be the annual average ERA-Interim temperature (which implies $\partial_{t} \bar{T}^{0}=0$ ) and the annual mean SWOOSH constituent mixing ratios. The latter are then perturbed to their annually varying climatologies. One could alternatively use the annually varying temperature climatology as the base state (e.g. Fueglistaler et al., 2011), but this was found to have a negligible impact on the simulated temperature response. The use of a time-independent background state was also easier to implement in the dynamical calculations reported in Sect. 5.

\section{SEFDH calculations of temperature response}

\subsection{Temperature response due to annual ozone cycle}

Figure 2 shows differences in ozone mixing ratios from the annual mean over the tropics. The annual cycle in tropical lower-stratospheric ozone mixing ratios, and in particular the large amplitude of the annual cycle relative to annual mean values, is well known on the basis of ozonesondes (e.g. Logan, 1999) and satellite data (e.g. Randel et al., 2007; Tegtmeier et al., 2013). The height and latitude structure of the annual ozone cycle at low latitudes from SWOOSH is shown in Fig. 2a, and the corresponding latitudinal structure at $70 \mathrm{hPa}$ is shown in Fig. 2b. Ozone mixing ratios are lowest across the tropics in $\mathrm{NH}$ winter and spring and highest in 

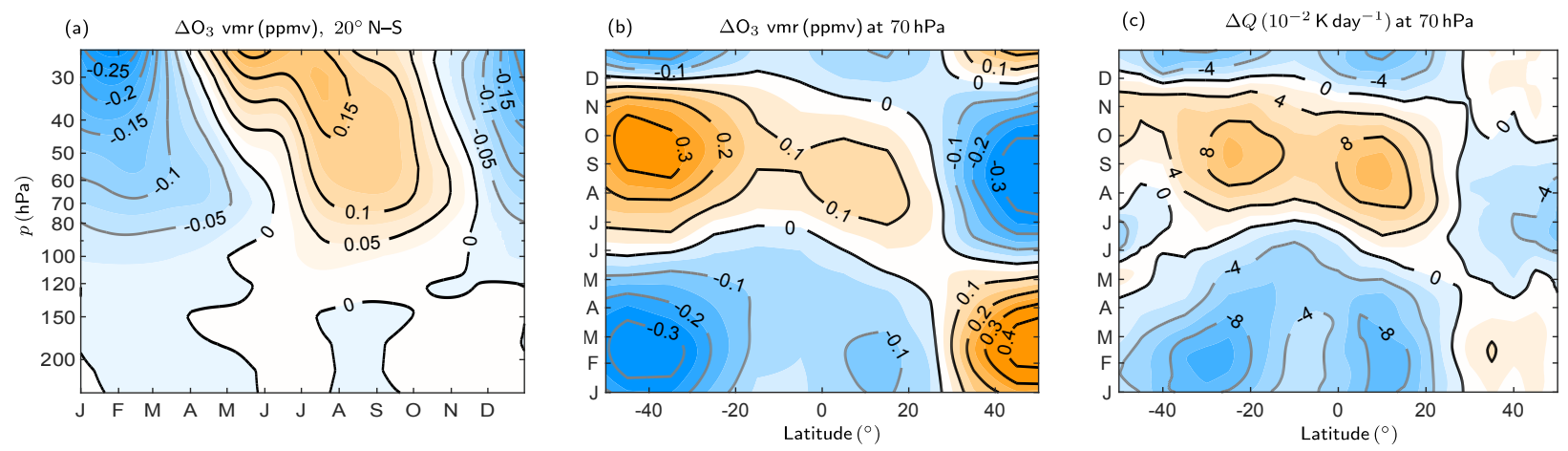

Figure 2. Ozone volume mixing ratio (ppmv) from the SWOOSH dataset plotted as a difference from the annual mean (a) averaged between $20^{\circ} \mathrm{N}$ and $20^{\circ} \mathrm{S}$ and (b) at $70 \mathrm{hPa}$. (c) The total change in heating rate (longwave and shortwave) due to the annual ozone cycle, assuming that temperatures are fixed at the annual average values.

$\mathrm{NH}$ summer and autumn. The cycle has a broad latitudinal structure, but the amplitude is substantially larger in the $\mathrm{NH}$ subtropics than in the SH subtropics (Stolarski et al., 2014). Whilst the amplitude of the annual cycle in ozone mixing ratio increases with height (Fig. 2a), the amplitude as a proportion of the annual mean mixing ratio (i.e. the "relative amplitude") is largest at about $80 \mathrm{hPa}$ and decreases upward above that level (e.g. Randel et al., 2007, their Fig. 3).

The factors that determine the temperature response to a change in ozone mixing ratio in the TTL are explained in detail in Appendix A1. The main effect of a reduction in ozone in a particular shallow layer is to decrease heating in that layer through both decreased shortwave absorption and decreased absorption of upwelling longwave radiation, with the latter being the dominant effect in the TTL. The decreased opacity of the perturbed layer also leads to increased longwave heating in overlying layers. As an illustration, Fig. 2c shows the change in heating rate at $70 \mathrm{hPa}$ due to the annual ozone cycle, assuming that temperatures are fixed at the annual average values. (The quantity plotted is $\bar{Q}_{\mathrm{rad}}\left(\bar{T}^{0}, \bar{\chi}_{\mathrm{O}_{3}}^{0}+\Delta \bar{\chi}_{\mathrm{O}_{3}}, \bar{\chi}_{\mathrm{H}_{2} \mathrm{O}}^{0}\right)-\bar{Q}_{\mathrm{rad}}\left(\bar{T}^{0}, \bar{\chi}_{\mathrm{O}_{3}}^{0}, \bar{\chi}_{\mathrm{H}_{2} \mathrm{O}}^{0}\right)$.)

The temperature response associated with the ozone anomalies in Fig. 2 predicted by the SEFDH calculation is shown in Fig. 3. A significant annual cycle in temperature is simulated across the tropics (averaged between $20^{\circ} \mathrm{N}$ and $20^{\circ} \mathrm{S}$ ), with cooler temperatures when ozone mixing ratios are relatively low, in $\mathrm{NH}$ winter, and warmer temperatures when ozone mixing ratios are relatively high, in $\mathrm{NH}$ summer.

In the vertical, the temperature response to ozone is largest between 90 to $70 \mathrm{hPa}$ with a peak-to-peak amplitude over the annual cycle of about $3.5 \pm 0.4 \mathrm{~K}$ at $70 \mathrm{hPa}$ and about $3.3 \pm 0.5 \mathrm{~K}$ at $90 \mathrm{hPa}$ (Fig. 3a; values are quoted with $95 \%$ confidence intervals; see Appendix B for details). The simulated temperature response has a lag of about 1.5 months compared to the annual cycle in ozone. The response essentially has the same sign at all levels because the change in ozone mixing ratios occurs over a relatively deep layer so that, at a given level, any effects of the reduction in upwelling radiation by increased ozone in the levels below are dominated by the increased absorption by ozone at that level. The latitudinal structure of the simulated temperature response at $70 \mathrm{hPa}$ is shown in Fig. 3b. Within the tropics, the latitudinal structure closely matches that of the ozone variations shown in Fig. 2b. Both are stronger in the NH subtropics than in the SH subtropics.

The temporal and latitudinal structure of the temperature response to ozone at $70 \mathrm{hPa}$ is similar to those presented by Fueglistaler et al. (2011), who used ozone from the HALOE dataset and the Edwards and Slingo radiation code. However, the peak-to-peak amplitude we obtain, $3.5 \pm 0.4 \mathrm{~K}$, is substantially larger than they report $(\sim 2 \mathrm{~K})$. The $3 \mathrm{~K}$ amplitude found by Chae and Sherwood (2007) is closer to our result and provides a useful comparison since the assumptions underlying the time-dependent 1-D radiative-convective calculation from which it was obtained are very similar to those in the SEFDH approach. The recent study of Gilford and Solomon (2017), which used the same SEFDH approach with a different radiation code and ozone climatology, finds an amplitude of $3.1 \mathrm{~K}$, which is more consistent with the present results.

There are several possible causes for the quantitative differences between results, including differences in the satellite ozone datasets employed (which reflect real observational uncertainties) and differences in radiation schemes. Our quoted uncertainties for the magnitude of the annual cycle in temperature at different levels (refer to previous text and/or Appendix B) are intended to estimate the effect of the uncertainty in the precision of the observational data. While we have not been able to isolate the specific reason for the different results, it is also clear from further sensitivity tests, reported in Appendix C, that the quantitative temperature response to the annual ozone cycle has significant sensitivity to the annual mean background ozone concentrations. For example, if the background ozone concentration is reduced at each level by about $10 \%$ (which corresponds to about 2 standard deviations of the estimated uncertainty in the annual 
(a)

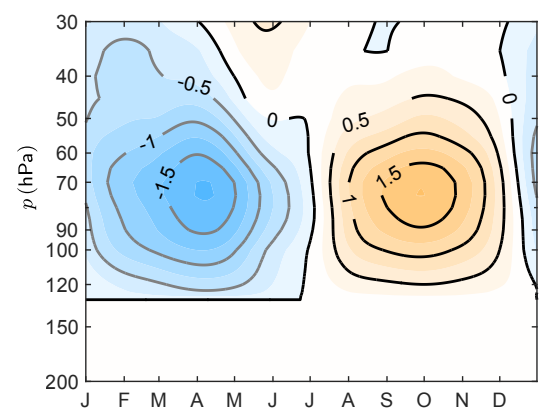

(b)

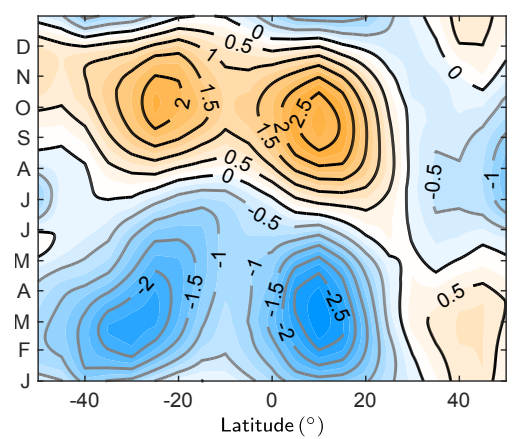

(c)

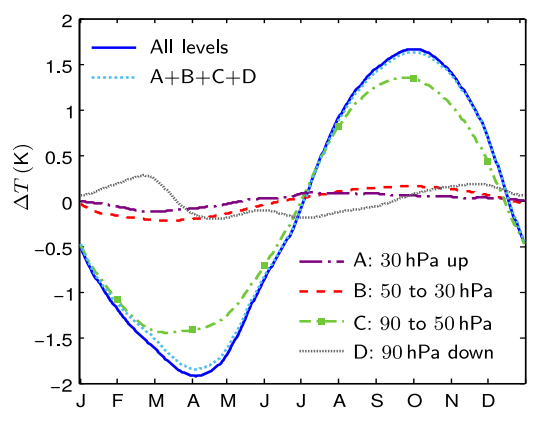

Figure 3. SEFDH temperature change $(\mathrm{K})$ due to the annual cycle in ozone. All other trace gases are kept at their annual mean values. (a) Temperature change averaged between $20^{\circ} \mathrm{N}$ and $20^{\circ} \mathrm{S}$. (b) Temperature change at $70 \mathrm{hPa}$. (c) Temperature changes at $70 \mathrm{hPa}$ and averaged between $20^{\circ} \mathrm{N}$ and $20^{\circ} \mathrm{S}$ calculated with the annual cycle in ozone imposed within different pressure ranges. Outside of each range and including the pressure level at the lower bound (in terms of height) of the range, the ozone mixing ratio is kept at the annual mean value.

mean ozone mixing ratio), the peak-to-peak amplitude of the annual cycle is reduced by about $5 \%$.

To investigate the role of ozone variations in different layers of the TTL for the observed annual cycle, the SEFDH calculation was repeated with the annual cycle in ozone imposed only within a set of sub-layers: 1000 to 90,90 to 50,50 to 30 , and 30 to $1 \mathrm{hPa}$ (see Fig. 3c). Outside the given layer, and including the pressure level at the lower bound of the range (in height), ozone is left at the annual mean value. The annual cycle in ozone in the region 90 to $50 \mathrm{hPa}$ accounts for about $80 \%$ of the annual temperature cycle at $70 \mathrm{hPa}$. A similar result is found at $90 \mathrm{hPa}$, where about $60 \%$ of the temperature variation is driven by ozone variations in the 100 to $80 \mathrm{hPa}$ layer, $30 \%$ by those in the 80 to $50 \mathrm{hPa}$ layer, and $8 \%$ by those in the 50 to $30 \mathrm{hPa}$ layer, with the remainder coming from the other layers (not shown). The relation between ozone variations and the resulting temperature variations in the TTL region is therefore primarily local in the vertical.

To summarize the results of this subsection, we have shown using an SEFDH calculation that the annual ozone cycle can account for $3.5 \pm 0.4 \mathrm{~K}$ of the $8.2 \pm 0.3 \mathrm{~K}$ observed peak-to-peak amplitude of the annual cycle in tropical averaged temperature at $70 \mathrm{hPa}$. The response amounts to an even larger fraction of the observed annual cycle near the cold point, accounting for $3.3 \pm 0.5 \mathrm{~K}$ of the $5.8 \pm 0.2 \mathrm{~K}$ amplitude at $90 \mathrm{hPa}$ and $2.6 \pm 0.2 \mathrm{~K}$ of the $3.4 \pm 0.1 \mathrm{~K}$ amplitude at $100 \mathrm{hPa}$.

\subsection{Temperature response due to annual water vapour cycle}

Figure 4 shows the annual cycle in tropical water vapour mixing ratio anomalies from the SWOOSH dataset. The tropical average water vapour mixing ratios show a clear tape recorder signal of tilted bands of positive and negative anomalies in the vertical (Fig. 4a). Above the tropopause, the amplitude of the annual water vapour cycle is largest at around $90 \mathrm{hPa}$ where temperatures are coldest, consistent with the fact that water vapour is directly controlled by temperature. The amplitude of the annual cycle increases substantially below $150 \mathrm{hPa}$.

Since the vertical structure of the annual water vapour cycle is quite complex relative to that of ozone, we show the latitudinal structure at several different levels, 70, 90, and $100 \mathrm{hPa}$ (Fig. 4b-d). Some hemispheric differences are apparent, especially at $100 \mathrm{hPa}$. The amplitude in the annual cycle in water vapour is greater in the $\mathrm{NH}$, with the largest values near the cold point in September.

The radiative factors that determine the temperature response to a change in water vapour in the TTL are described in detail in Appendix A2. The main effect of a reduction in water vapour within a particular shallow layer is cooling below the layer and heating within and above it. The reduction in water vapour implies less local emission of longwave radiation and therefore reduced absorption above and below (hence the cooling), together with less absorption of upwelling radiation within the layer and increased absorption above. Within the layer the effect of reduced local emission is stronger, so the net effect is heating. Above the layer the effects of increased absorption of upwelling radiation dominate, leading to net heating.

Figure 5a shows the temperature response from the SEFDH calculation for the water vapour changes in Fig. 4. The temperature response peaks near $90 \mathrm{hPa}$, i.e. at a lower altitude than the maximum response to ozone (see Fig. 3a). The peak-to-peak amplitude averaged between $20^{\circ} \mathrm{N}-\mathrm{S}$ is $0.9 \pm 0.1 \mathrm{~K}$ at $70 \mathrm{hPa}, 1.1 \pm 0.1 \mathrm{~K}$ at $90 \mathrm{hPa}$, and $1.0 \pm 0.05 \mathrm{~K}$ at $100 \mathrm{hPa}$. In contrast to the ozone response, the water vapour response has a phase lag of about 1 month between $90 \mathrm{hPa}$ and $70 \mathrm{hPa}$. Note the phase lag of about 2 months between the annual cycle in water vapour mixing ratios at these levels (Fig. 4a). These phase lags result from the non-locality of the radiative response and the fact that the effect of one layer on another is being communicated in part by changes in tem- 

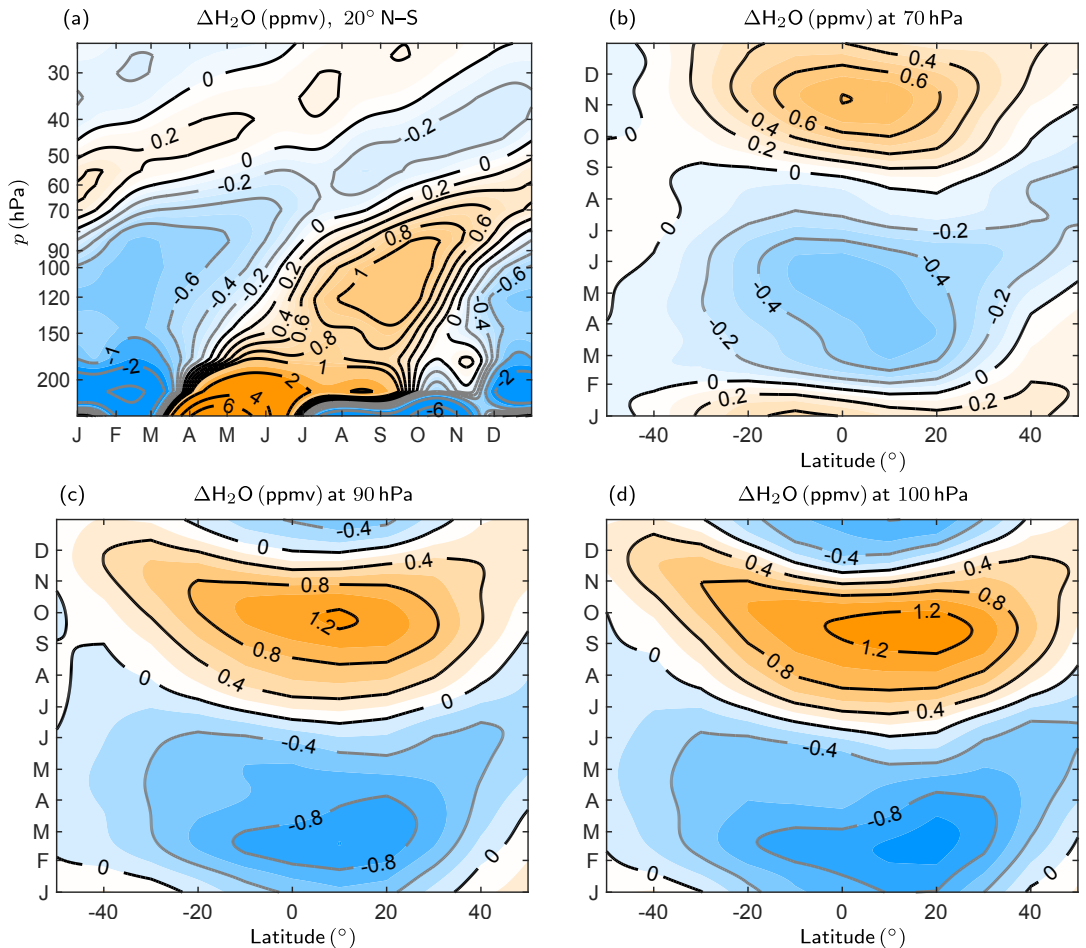

Figure 4. Water vapour volume mass mixing ratio (ppmv) from SWOOSH plotted as a difference from the annual mean (a) averaged over the region $20^{\circ} \mathrm{N}-20^{\circ} \mathrm{S}$, (b) at $70 \mathrm{hPa}$, (c) at $90 \mathrm{hPa}$, and (d) at $100 \mathrm{hPa}$.
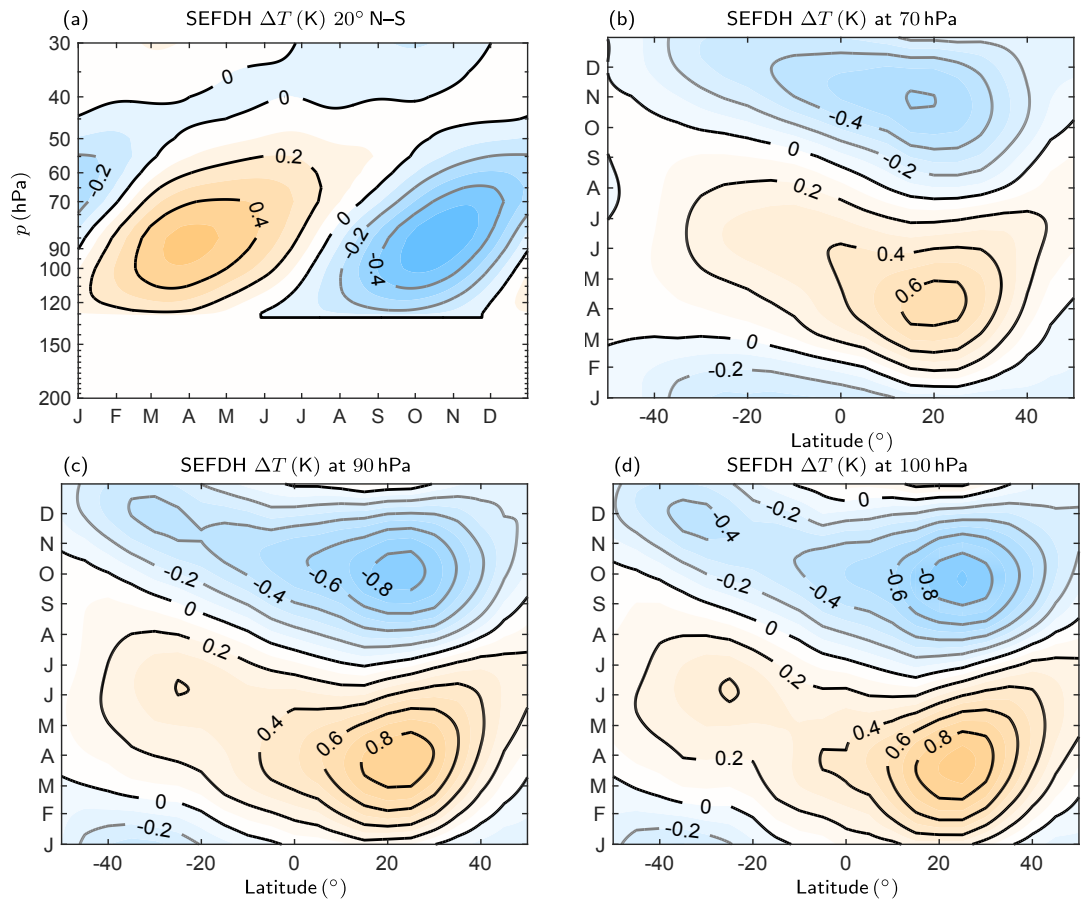

Figure 5. Temperature change (K) due to the annual water vapour cycle in an SEFDH calculation (a) averaged between $20^{\circ} \mathrm{N}$ and $20^{\circ} \mathrm{S}$, (b) at $70 \mathrm{hPa}$, (c) at $90 \mathrm{hPa}$, and (d) at $100 \mathrm{hPa}$. 

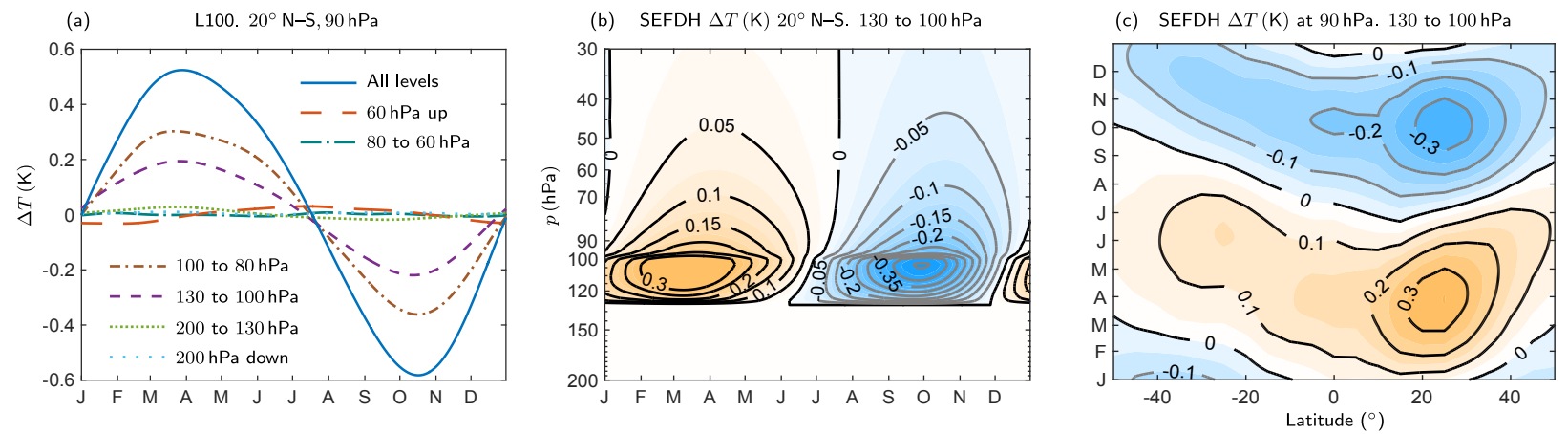

Figure 6. Annual cycle temperature changes $(\mathrm{K})$ at $90 \mathrm{hPa}$ calculated using SEFDH with the annual cycle in water vapour imposed within different pressure ranges. Outside of this range and on the pressure level at the lower bound (in terms of height) of the range, the water vapour mixing ratio is kept at the annual mean value. The plots are averaged between $20^{\circ} \mathrm{N}$ and $20^{\circ} \mathrm{S}$. The contributions from each layer add up linearly to reproduce the total change (not shown). The temperature change $(\mathrm{K})$ for the case in (a) where the annual water vapour cycle is imposed only from 100 to $130 \mathrm{hPa}$ is shown in (b) averaged between $20^{\circ} \mathrm{N}$ and $20^{\circ} \mathrm{S}$ and in (c) at $90 \mathrm{hPa}$.

perature, and hence changes in radiation, in the intermediate layers. The temperature response in the range 100 to $70 \mathrm{hPa}$ is, broadly speaking, opposite in phase to the observed annual cycle in temperatures (Fig. 1a) and the response to ozone (Fig. 3a).

Figure $5 \mathrm{~b}-\mathrm{d}$ show that the water vapour response is largest in the NH subtropics at all three levels $(70,90$, and $100 \mathrm{hPa})$. In each case, the latitude of the maximum response is further north than the latitude of the maximum amplitude in the water vapour mixing ratios at that level. The fact that there is no simple relation between the latitude-time structure of the SEFDH-predicted annual cycle in temperature at a given level and the latitude-time structure of the water vapour mixing ratios at that level is further evidence for important nonlocal contributions in the vertical from water vapour to the temperature variations.

As in the previous section, we examine these non-local contributions further by imposing the water vapour changes only within a set of sub-layers: 1000 to 200,200 to 130,130 to 100,100 to 80,80 to $60 \mathrm{hPa}$, and 60 to $1 \mathrm{hPa}$. Typical results are illustrated by Fig. 6a, which shows the response at $90 \mathrm{hPa}$ for each calculation. The total peak-to-peak amplitude is $1.1 \pm 0.1 \mathrm{~K}$, which consists of a local contribution from the 80 to $100 \mathrm{hPa}$ layer of $0.7 \mathrm{~K}$ and a substantial non-local contribution of $0.4 \mathrm{~K}$ from the 100 to $130 \mathrm{hPa}$ layer. Contributions from above $80 \mathrm{hPa}$ and from below $130 \mathrm{hPa}$ are small. The net contribution from the 130 to $200 \mathrm{hPa}$ layer is small in the $20^{\circ} \mathrm{N}-20^{\circ} \mathrm{S}$ average as a result of cancellations between the Northern and Southern Hemisphere temperature changes. There is also a large meridional gradient in water vapour, resulting in a larger temperature change in the Northern Hemisphere which is about $15 \%$ of the temperature change at $90 \mathrm{hPa}$ and $20^{\circ} \mathrm{N}$ (not shown).

Further illustration is given in Fig. 6b, which shows the time evolution of the temperature response at all levels when the water vapour perturbation is confined to 130 to $100 \mathrm{hPa}$.
In this layer, the water vapour anomaly is at a minimum in February-March and at a maximum in September-October. The features of the response described above are all visible except that there is no cooling below $130 \mathrm{hPa}$ due to the SEFDH temperature constraint. Figure $6 c$ shows the same temperature response plotted at $90 \mathrm{hPa}$. Comparing it to Fig. 5c (note the different contour interval), the 100 to $130 \mathrm{hPa}$ region contributes up to about $35 \%$ of the total response at $90 \mathrm{hPa}$. The peak response is centred at around $25^{\circ} \mathrm{N}$, demonstrating that the maximum response at $90 \mathrm{hPa}$ (Fig. 5c) is shifted northwards by non-local effects. Further sensitivity tests show that, unlike the case with ozone, the temperature response is not very sensitive to changes in the background value of water vapour (considering changes typical of interannual variations within the range of years covered by the SWOOSH dataset).

Gilford and Solomon (2017) find a response to water vapour changes with a peak-to-peak amplitude of $0.6 \mathrm{~K}$ at $70 \mathrm{hPa}, 0.9 \mathrm{~K}$ at $85 \mathrm{hPa}$, and $0.5 \mathrm{~K}$ at $100 \mathrm{hPa}$. These values are smaller than the amplitudes (respectively $0.9 \mathrm{~K}$ and $1.1 \mathrm{~K}$ for $90 \mathrm{hPa}$ and $1.0 \mathrm{~K}$ ) we report above, particularly at $100 \mathrm{hPa}$ but the difference may be in part explained by the fact that our calculations include water vapour variations down to $130 \mathrm{hPa}$. When, following Gilford and Solomon (2017), we include water vapour variations only above $117 \mathrm{hPa}$, we obtain peak-to-peak amplitudes of $0.8,1$ (for $85 \mathrm{hPa}$ ), and $0.8 \mathrm{~K}$ closer to their results.

\subsection{Temperature response to annual cycle in both constituents and dynamical heating}

Figure 7a, for $70 \mathrm{hPa}$, and Fig. $7 \mathrm{~b}$, for $90 \mathrm{hPa}$, show the combined effects of the annual ozone and water vapour cycles on temperature in an SEFDH calculation. These figures also show the observed annual cycle in temperature, the estimated annual cycle in temperature due to the annual cycle in dynamical heating (based on ERA-Interim data; see Sect. 4 
(a)

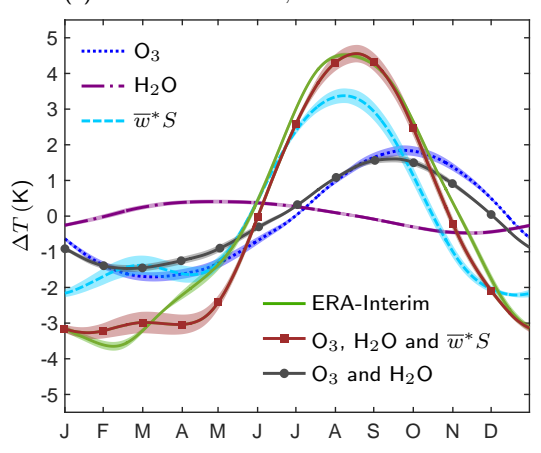

(b)

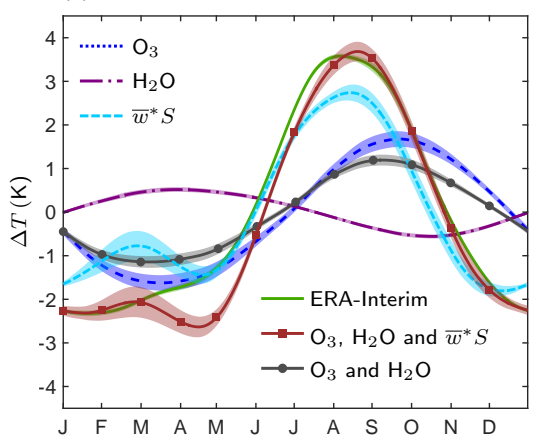

(c)

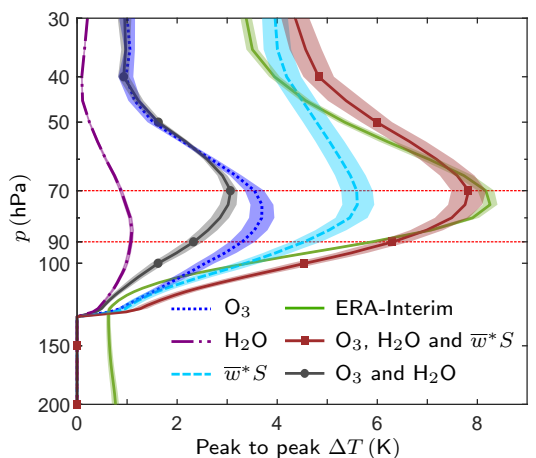

Figure 7. Temperature changes $(\mathrm{K})$ calculated using the SEFDH method with annual cycles in ozone and water vapour and from the modified SEFDH method (Sect. 4) for the dynamical heating. The plots are averaged between $20^{\circ} \mathrm{N}$ and $20^{\circ} \mathrm{S}$ at (a) $70 \mathrm{hPa}$ and (b) $90 \mathrm{hPa}$. The ERAInterim annual temperature cycle is also shown. Note that the vertical axes are different in (a, b). (c) The peak-to-peak amplitude of the temperature change averaged between $20^{\circ} \mathrm{N}$ and $20^{\circ} \mathrm{S}$. Note that there is a phase difference between the temperature from the annual water vapour and ozone cycles. Shadings show $95 \%$ confidence intervals arising from uncertainties in the datasets (see Appendix B for more details).

for further details), and the estimated annual cycle due to the combined effects of ozone, water vapour, and dynamical heating. To a good approximation the combined effect of ozone and water vapour is simply the sum of the individual effects discussed in Sects. 3.1 and 3.2.

At $70 \mathrm{hPa}$ (Fig. 7a), ozone and water vapour together can account for an annual cycle in temperature of about $2.8 \pm 0.3 \mathrm{~K}$ peak-to-peak, i.e. about $35 \%$ of the observed annual cycle in temperature. The cancellation between the effects of ozone and water vapour on temperature is strongest at $90 \mathrm{hPa}$ (Fig. 7b), with the combined amplitude being about $2.3 \pm 0.4 \mathrm{~K}$ peak-to-peak, i.e. again about $40 \%$ of the observed annual cycle. At $100 \mathrm{hPa}$, the combined amplitude is about $1.5 \pm 0.4 \mathrm{~K}$ peak-to-peak or about $45 \%$ of the observed annual cycle (not shown). Thus, while the estimated contribution of dynamical heating to the annual cycle in temperatures is substantially smaller than the observed annual cycle (Fig. 7a-c), when the contributions from dynamical heating, ozone, and water vapour are combined the result is in remarkably good agreement with the observed annual cycle, both in amplitude and in phase.

In summary, the combined effects of ozone and water vapour variations exert a substantial radiative influence on the annual cycle in TTL temperatures and the lower stratosphere above. The estimated radiative effect of ozone and water vapour and the observed annual cycle both peak in amplitude at $70 \mathrm{hPa}$. The fractional effect of ozone and water vapour relative to the annual cycle is substantial throughout the TTL, including at the cold point, where temperatures control the entry values of stratospheric water vapour.

\section{Vertical structure of the annual temperature cycle}

The annual cycle in tropical lower-stratospheric temperature is largest over a shallow layer from 100 to $50 \mathrm{hPa}$, with a maximum amplitude at $70 \mathrm{hPa}$ (Fig. 1c). This vertical structure has been attributed by Randel et al. (2002) to the presence of long radiative timescales in this region. In this section, we reconsider the question of whether the location of the maximum variation in tropical temperatures over the annual cycle is due to the structure of the major radiative and dynamical forcings and/or to the structure of the background radiative environment.

Figure 8a shows the variation in tropical averaged $\bar{w}^{*}$, in height and time, and reveals a systematic decrease in amplitude with increasing height from 150 to $50 \mathrm{hPa}$. Figure $8 \mathrm{~b}$ shows the full dynamical heating term, $\bar{w}^{*} \bar{S}$, and Fig. 8c shows the same quantity with the annual mean, $\left\langle\bar{w}^{*} \bar{S}\right\rangle$, removed. The annual cycle in dynamical heating is larger above $100 \mathrm{hPa}$ compared to below and rather uniform in amplitude over a deep layer that extends from $90 \mathrm{hPa}$ up to about $40 \mathrm{hPa}$ (Fig. 8c). This behaviour is strongly influenced by the annual cycle in upwelling (Fig. 8d), and in the region 120 to $90 \mathrm{hPa}$, it is further modified by the annual cycle in static stability (Fig. 8e), which causes a reduction in the annual cycle in dynamical heating around $100 \mathrm{hPa}$. The peak-to-peak amplitude of the annual cycle in dynamical heating in the lower stratosphere is around 0.15 to $0.2 \mathrm{~K} \mathrm{day}^{-1}$. This amplitude does not decrease below the tropopause as rapidly as does the observed peak-to-peak amplitude of temperature (Fig. 1a).

To probe the effects of these heating structures on the annual temperature cycle, we now consider a set of SEFDHlike calculations forced by a set of specified dynamical heating structures. This is achieved by imposing an additional dynamical heating, $\Delta \bar{Q}_{\mathrm{dyn}}$, on the right-hand side 

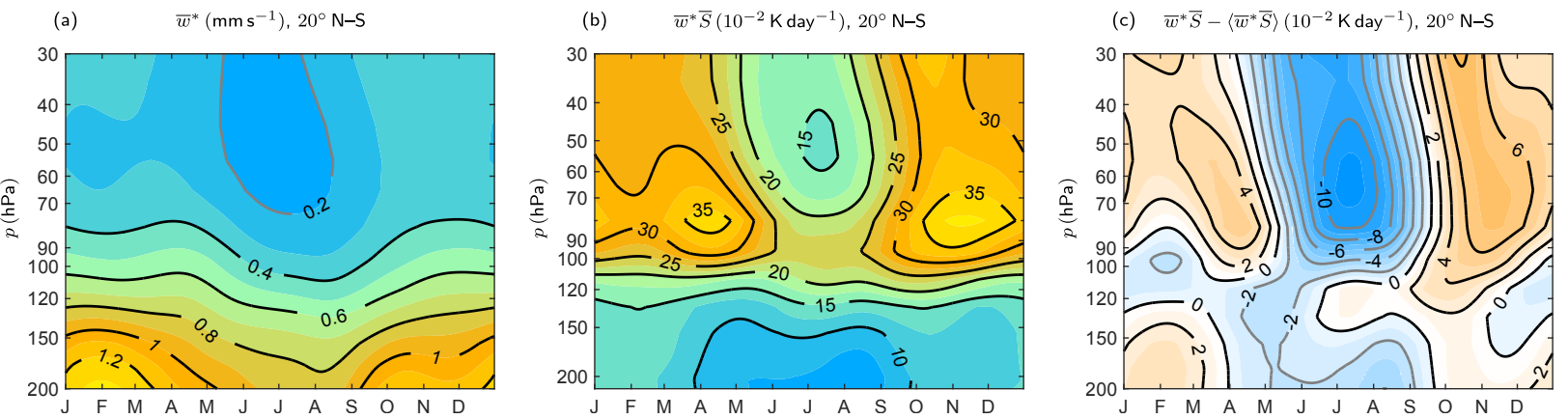

(d) $\left(\bar{w}^{*}-\left\langle\bar{w}^{*}\right\rangle\right)\langle\bar{S}\rangle\left(10^{-2} \mathrm{~K}_{\text {day }}{ }^{-1}\right), 20^{\circ} \mathrm{N}-\mathrm{S}$

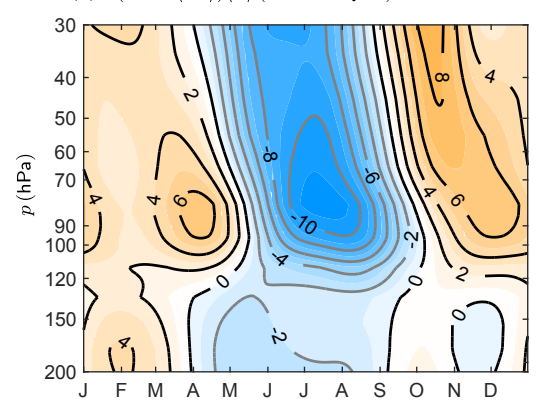

(e) $\left\langle\bar{w}^{*}\right\rangle\left(\bar{S}-\left\langle\bar{S}^{*}\right\rangle\right)\left(10^{-2} \mathrm{Kday}^{-1}\right), 20^{\circ} \mathrm{N}-\mathrm{S}$

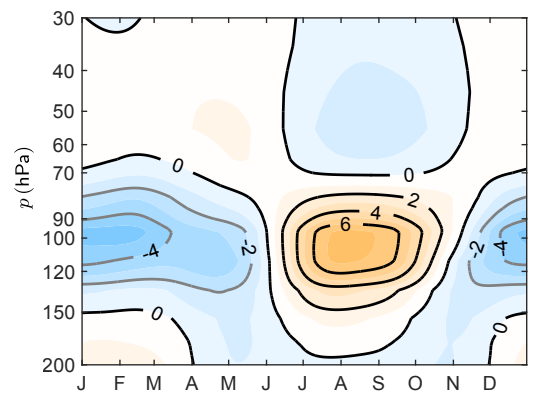

Figure 8. Data from ERA-Interim averaged between 1991 to 2010 and $20^{\circ} \mathrm{N}-20^{\circ} \mathrm{S}$. Monthly averages are interpolated to daily values to smooth out the noise in the upwelling field. (a) Mean residual vertical velocity, $\bar{w}^{*}$. (b) Dynamical heating term $\bar{w}^{*} \bar{S}\left(=-\bar{Q}_{\text {dyn }}\right.$ ). (c) Same as (b) but with the annual mean removed. (d) $\left(\bar{w}^{*}-\left\langle\bar{w}^{*}\right\rangle\right)\langle\bar{S}\rangle$ component of the dynamical heating. (e) $\left\langle\bar{w}^{*}\right\rangle(\bar{S}-\langle\bar{S}\rangle)$ component of the dynamical heating.

of Eq. (1). To determine whether the localization of temperature variation is a result of the structure of the radiative environment, we first consider an idealized dynamical heating perturbation with no vertical structure: $\Delta \bar{Q}_{\text {dyn }}=$ $-0.1 \cos (2 \pi t / 365) \mathrm{Kday}^{-1}$. For this and the next few calculations, we remove the constraint on temperatures below $130 \mathrm{hPa}$, permitting them to evolve freely in response to the radiative perturbations. Any vertical dependence in the response to this heating will therefore be solely determined by vertical structure in the temperature-dependent part of the radiative heating.

The resulting temperature change for this case is shown in Fig. 9a. The amplitude of the response is largest in a layer centred on $100 \mathrm{hPa}$. The phase lag with respect to the imposed heating is also largest in this layer and equal to about 60 days. This is consistent with a Newtonian cooling model in which the radiative relaxation timescale was a maximum of about 60 days at $100 \mathrm{hPa}$, roughly at the cold point, consistent with theoretical expectations (Bresser et al., 1995; Fels, 1982). The implied radiative timescales peak over a broader height range than those found by Randel et al. (2002) and in particular do not show such a strong reduction below $100 \mathrm{hPa}$. Randel et al. (2002) inferred damping timescales from the cross-correlation between the annual components of analysed $\bar{T}$ and $\bar{w}^{*}$, which implicitly includes non-local effects such as those of non-radiative processes operating in the upper troposphere. This is also true of the supporting radiative calculations they performed on the basis of observed temperature anomalies. As demonstrated below, the tropospheric processes have a substantial effect on the relaxation of temperature anomalies even in the lower stratosphere, in part because of the strong dependence of radiative timescales on the vertical scale of the imposed temperature perturbation (Fels, 1982).

The response to the annual cycle in $\bar{w}^{*} \bar{S}$ from ERAInterim (Fig. 8c) is now considered. For convenience, we set the dynamical heating below $450 \mathrm{hPa}$ to have the same value as at $450 \mathrm{hPa}$. This does not affect the main conclusions of this calculation. The corresponding temperature response is shown in Fig. 9b. The vertical structure in the dynamical heating significantly modifies the vertical structure in the temperature response. In particular, the fact that the dynamical heating is larger at $70 \mathrm{hPa}$ than at $100 \mathrm{hPa}$ leads to a larger temperature response at $70 \mathrm{hPa}$ than at $100 \mathrm{hPa}$, in contrast to the response to the uniform dynamical heating shown in Fig. 9a. Therefore, the vertical structure in amplitude of the annual temperature cycle driven by dynamical heating is determined by both the background radiative environment and by the vertical structure of the dynamical heating itself.

To further illustrate this, Fig. 9c shows the temperature response to the ERA-Interim dynamical heating assuming a constant radiative relaxation timescale of 40 days. The response is a good approximation to that in Fig. 9b around 

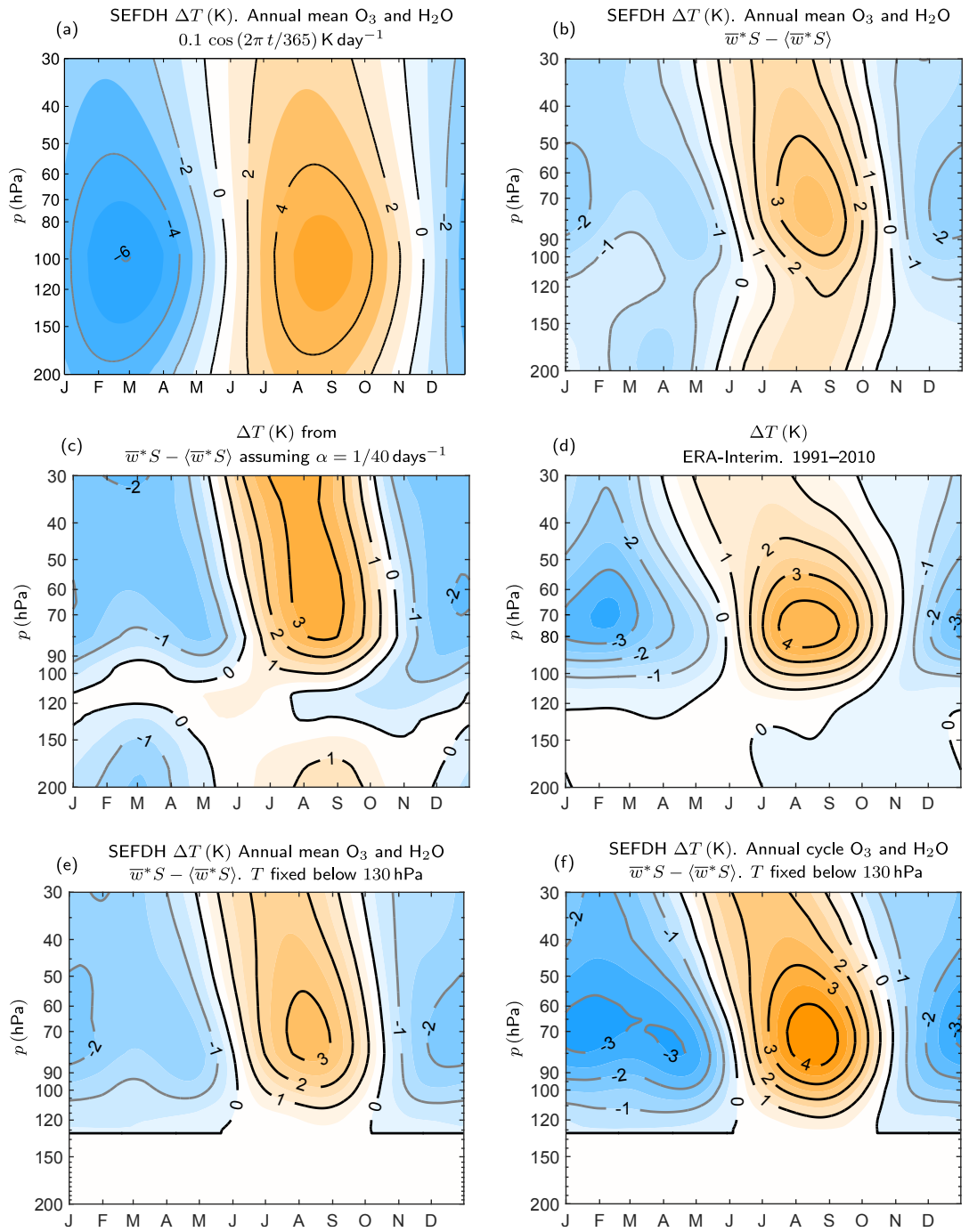

Figure 9. Temperature change from the annual mean averaged between $20^{\circ} \mathrm{N}$ and $20^{\circ} \mathrm{S}$. (a) An SEFDH-like calculation with a perturbation of $-0.1 \cos (2 \pi t / 365) \mathrm{Kday}^{-1}$ is added to the dynamical heating with annual mean ozone and water vapour. (b) The temperature change from the annual cycle in the ERA-Interim dynamical heating, $\bar{w}^{*} S-\left\langle\bar{w}^{*} S\right\rangle$, shown in Fig. 8c. (c) Temperature change due to the annual cycle in the ERA-Interim dynamical heating but assuming a constant radiative relaxation rate of $1 / 40$ days ${ }^{-1}$. (d) ERA-Interim annual mean temperature averaged between 1991 to 2010 (same as Fig. 1a). (e) Similar to (b) but with temperature held fixed at the annual mean below $130 \mathrm{hPa}$. (f) Similar to (e) but with the additional perturbation from the annual cycle in ozone and water vapour included.

$70 \mathrm{hPa}$, suggesting that the radiative timescale appropriate for the dynamical heating perturbation is around 40 days, somewhat shorter than that inferred from Fig. 9a and consistent with the smaller vertical length scale of the imposed perturbation. However, there remains below $100 \mathrm{hPa}$ a peak-topeak amplitude in the temperature that is significantly larger than is observed. If we assume that this calculation of the dynamical heating provides a reasonable estimate of the magnitude of the dominant terms in the thermodynamic budget of the upper troposphere, this suggests that upper-tropospheric processes provide a stronger constraint on temperature perturbations than do clear-sky radiative processes. Further calculations (results not shown) suggest (subject to the preced- ing assumption) that the effective timescale of this constraint is approximately 10 days.

To illustrate the implications of the observed tropospheric constraint on temperatures, we reintroduce the clamp on the temperatures below $130 \mathrm{hPa}$ in the SEFDH calculation as a simple representation of these processes. Figure 9e shows the resulting temperature response to the same dynamical heating perturbation imposed in Fig. 9b. The tropospheric constraint causes the maximum amplitude of the response to shift upwards from around $80 \mathrm{hPa}$ to about $70 \mathrm{hPa}$ and reduces the magnitude of the peak response compared to Fig. 9b. It is clear, therefore, that this upper-tropospheric constraint has a significant radiative effect on the region above. 
We now add the radiative heating perturbations from the annual ozone and water vapour cycles to the ERA-Interim dynamical heating to produce Fig. 9f. The net effect of the annual ozone and water vapour cycles, as shown in Sect. 3.3, is to increase the amplitude of the temperature response. This produces an annual cycle with a structure that is in better agreement than that in Fig. 9e with the ERA-Interim annual cycle, Fig. 9d, with a more pronounced peak at $70 \mathrm{hPa}$.

In summary, the calculations reported in this section suggest that the vertical structure of the peak-to-peak amplitude in the annual cycle of temperatures arises from a combination of several effects. In the absence of the implied uppertropospheric constraint, we find that clear-sky radiative processes produce long radiative timescales over a deep layer centred around $100 \mathrm{hPa}$ and would, in the absence of other effects, imply a similarly deep structure in the amplitude of the annual cycle. The vertical structure in the dynamical heating and radiative heating from constituent changes, both of which exhibit a peak in the region around 80 to $70 \mathrm{hPa}$, combined with the tropospheric constraint, lead to a shallower vertical structure with a stronger response at 70 than at $100 \mathrm{hPa}$.

\section{The effect of zonally symmetric dynamical adjustment}

We will now consider the temperature response to annual cycles in ozone and water vapour, relaxing the SEFDH assumption to include zonally symmetric dynamical adjustment. This approach assumes no change in the zonally averaged wave force, which might well be a significant part of the full dynamical response in a three-dimensional atmosphere, even if the imposed annual cycles in ozone and water vapour are zonally symmetric. We discuss the implications of this simplifying assumption in Sect. 6 below. The zonally symmetric dynamical response problem has been considered in many previous papers (e.g. Plumb, 1982; Garcia, 1987; Haynes et al., 1991). The expectation from this previous work is that the response to the heating implied by an imposed change in constituents will occur in part through dynamical heating, modifying the vertical and latitudinal structure of the temperature response. One important difference in our approach from these previous studies is that, rather than approximating the temperature-dependent part of the radiative heating by Newtonian cooling, we continue to use the modified Morcrette-Zhong and Haigh radiation code.

\subsection{Model description}

For the dynamical calculations, we use the University of Reading IGCM 3.1 (de F. Forster et al., 2000) which is a hydrostatic primitive equation model based on the original Hoskins and Simmons (1975) spectral dynamical model. This is set up with a minimal configuration that only in- cludes the dynamical core and the radiation code. Only the coefficients of the zonally symmetric spherical harmonics are retained, up to the total wave number 42 , resulting in an approximate latitudinal resolution of $3^{\circ}$. There are $60 \mathrm{lev}$ els equally spaced in log-pressure coordinates in the vertical with the model top at $50 \mathrm{~km}$. The velocities in the layer near the surface $\sigma>0.7$ are linearly damped as described in Held and Suarez (1994).

The temperature tendency in the model is set to be

$$
\begin{aligned}
& \partial_{t} \bar{T}+[\ldots]=(1-G(\phi, \sigma))\left(\bar{Q}_{\mathrm{rad}}(\bar{T}(t), \bar{\chi}(t))-\bar{Q}_{\mathrm{rad}}\left(\bar{T}^{0}, \bar{\chi}^{0}\right)\right) \\
& \quad-G(\phi, \sigma) \alpha\left(\bar{T}-\bar{T}^{0}\right),
\end{aligned}
$$

where the $[\ldots]$ represents other advective processes in the model and $G(\phi, \sigma)=0.5\left(1+\tanh \left(50\left(\sigma-\sigma_{\text {trop }}(\phi)\right)\right)\right)$. The notation $\bar{Q}_{\text {rad }}(\bar{T}(t), \bar{\chi}(t))$ is used to denote the instantaneous radiative heating rate, calculated from the radiation code, given vertical profiles of temperature, $\bar{T}(t)$, and concentration, $\bar{\chi}(t)$, of radiatively active species (meaning here ozone and water vapour, with the single symbol $\chi$ for brevity used to indicate both). The use of $G(\phi, \sigma)$ in Eq. (4), with $\sigma_{\text {trop }}(\phi)$ set to 0.13 , implies that the heating terms calculated from the radiative code dominate above $130 \mathrm{hPa}$, i.e. in the stratosphere, and the Newtonian cooling term dominates below $130 \mathrm{hPa}$, i.e. in the troposphere, with a smooth transition between the two regimes. The Newtonian cooling timescale is taken to be $1 / \alpha=10$ days. The radiative calculation is implemented in exactly the same way as in the SEFDH calculations in Sects. 3 and 4. We have verified that the stand-alone radiation code and the version in the model produce consistent longwave and shortwave heating rates.

The term $\bar{Q}_{\text {rad }}\left(\bar{T}^{0}, \bar{\chi}^{0}\right)$ is included so that with the annual mean species concentrations, $\bar{\chi}^{0}$, and the ERA-Interim annual mean temperature, $\bar{T}^{0}$, the heating term on the righthand side of Eq. (4) is 0 . Therefore, $\bar{T}^{0}$ is in principle an equilibrium state of the model. In practice, the effect of dissipative dynamical processes such as surface drag and hyperdiffusion means that if the model is initialized in state $\bar{T}^{0}$, it evolves towards a slightly different state $\bar{T}_{c}^{0}$. Differences between $\bar{T}_{c}^{0}$ and $\bar{T}^{0}$ are very small (e.g. less than $2 \mathrm{~K}$ in the tropical stratosphere), and we have verified that this does not affect the results presented below.

The dynamical response to the annual cycles in ozone and water vapour is calculated by considering the difference between a "perturbed" integration in which the annual cycles are included in $\bar{\chi}(t))$ in Eq. (4) and a "control" integration in which they are not; so $\bar{\chi}(t)=\bar{\chi}^{0}$. Both integrations are for 5 years, with $\bar{T}^{0}$ set as initial condition for each. The first 4 years is allowed as a spin-up period, during which there is an evolution from the state $\bar{T}^{0}$ to $\bar{T}_{c}^{0}$ as noted above and, in the case of the perturbed integration, an evolution of $\bar{T}$ towards a time-periodic annual cycle. The response, as presented in the remainder of Sect. 5 below, is then taken to 

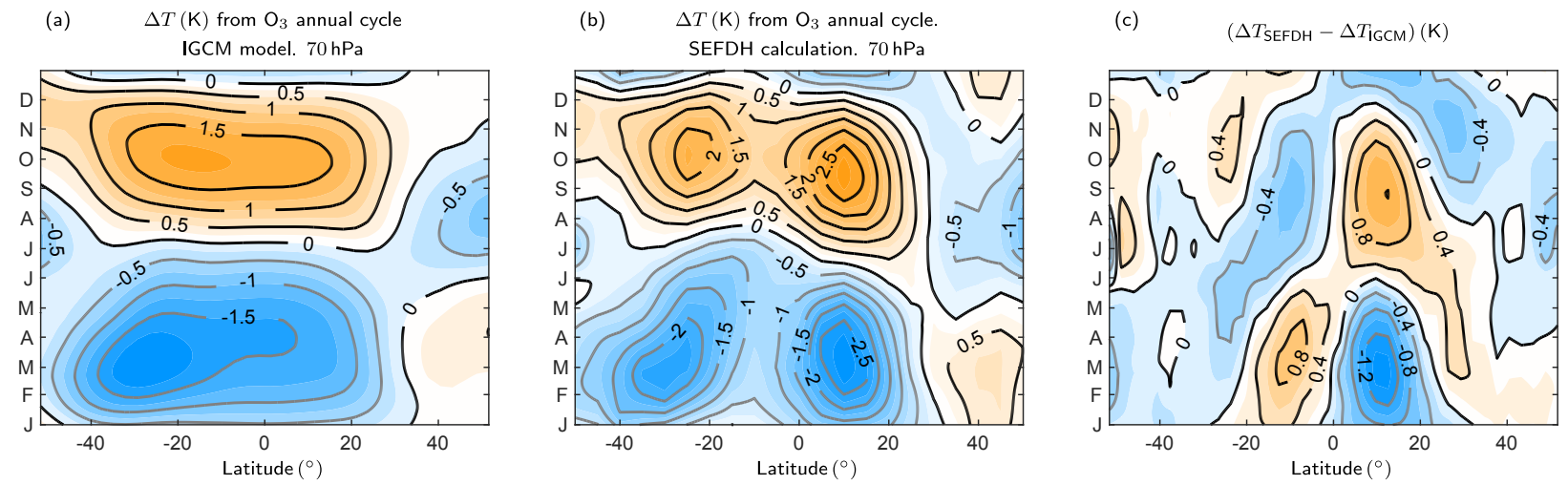

(d) $\Delta \bar{w}\left(\mathrm{~mm} \mathrm{~s}^{-1}\right)$ from $\mathrm{O}_{3}$ annual cycle

(e) $\quad \Delta T(\mathrm{~K})$ using $\Delta(\bar{w} \bar{S})$
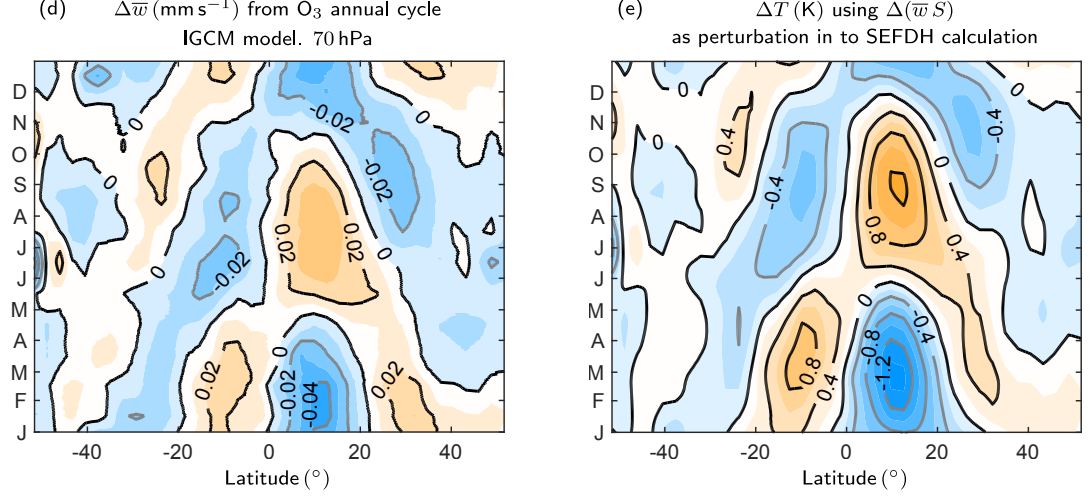

Figure 10. (a) Monthly temperature changes showing the annual cycle at $70 \mathrm{hPa}$ calculated using the idealized dynamical model (IGCM) with an annual cycle in ozone. (b) Figure $2 \mathrm{~b}$ is reproduced here for comparison and shows the corresponding SEFDH calculation at $70 \mathrm{hPa}$. (c) Difference in temperature change (K) between SEFDH calculation (b) and the IGCM calculation (a). (d) Change in upwelling in idealized dynamical model. (e) Temperature change at $70 \mathrm{hPa}$ calculated by imposing the term $\Delta(\bar{w} \bar{S})$ from the dynamical model as a perturbation to the SEFDH calculation. See main text for more details.

be the difference between the two integrations during the final year. (Note that the responses are shown at the nearest model levels to 70,90 , and $100 \mathrm{hPa}$, which are $68.8,87.3$, and 98.3 hPa respectively.) The label IGCM will be used throughout the remainder of the paper, in the text and the figures, to denote the dynamical calculation, as just described, and to distinguish it from the SEFDH calculation.

\subsection{Temperature response to annual ozone cycle}

Figure $10 \mathrm{a}$ and $\mathrm{b}$ compare the temperature change at $70 \mathrm{hPa}$ caused by the annual cycle in ozone in the dynamical model and in the SEFDH calculation respectively (Fig. 10b is identical to Fig. $3 b$ but is included here for ease of comparison). Figure 10c shows the difference between the two. The figures show the importance of including the dynamical adjustment, which tends to broaden the temperature response in latitude in the tropical region, making it more symmetric about the Equator. Note, in particular, the effect on the off-equatorial maximum at about $10^{\circ} \mathrm{N}$ in the SEFDH calculation, which is no longer a distinct isolated feature in the dynamical calculation.
This difference between the dynamical and SEFDH calculations is as expected from the previously cited theoretical work on the zonally symmetric dynamical response adjustment problem. In the dynamical calculation there is a change in vertical velocity, $\bar{w}^{*}$, and in consequence, the applied heating is balanced in part by $\partial_{t} \bar{T}$ and $\bar{Q}_{\text {rad }}$ (the "temperature part" of the response), and in part by a response in dynamical heating (principally $\bar{w}^{*} \bar{S}$ ). In considering the annual cycle in the TTL, timescales are comparable to or somewhat larger than the radiative damping time, implying that the change in the temperature-dependent part of $\bar{Q}_{\mathrm{rad}}$ is substantial (but not necessarily dominant) in the temperature part of the response. On the basis of simple scaling arguments which follow as a corollary to those presented, for example in Garcia (1987) or Haynes (2005), the dynamical heating response is then expected to dominate over the temperature part of the response when the latitudinal scale, $L$, is less than $(N D /(2 \Omega \sin \phi))\left(\omega_{\mathrm{a}} / \alpha\right)^{1 / 2}$, where $N$ is the buoyancy frequency, $D$ is the vertical scale of the heating, $\Omega$ is the rotation rate, and $\omega_{\mathrm{a}}$ is the annual frequency. This condition holds when the latitudinal scale $L$ is sufficiently small or at sufficiently low latitudes. Close to the Equator, this criterion is modified to $L$ being less than $(N D a /(2 \Omega))^{1 / 2}\left(\omega_{\mathrm{a}} / \alpha\right)^{1 / 4}$, 

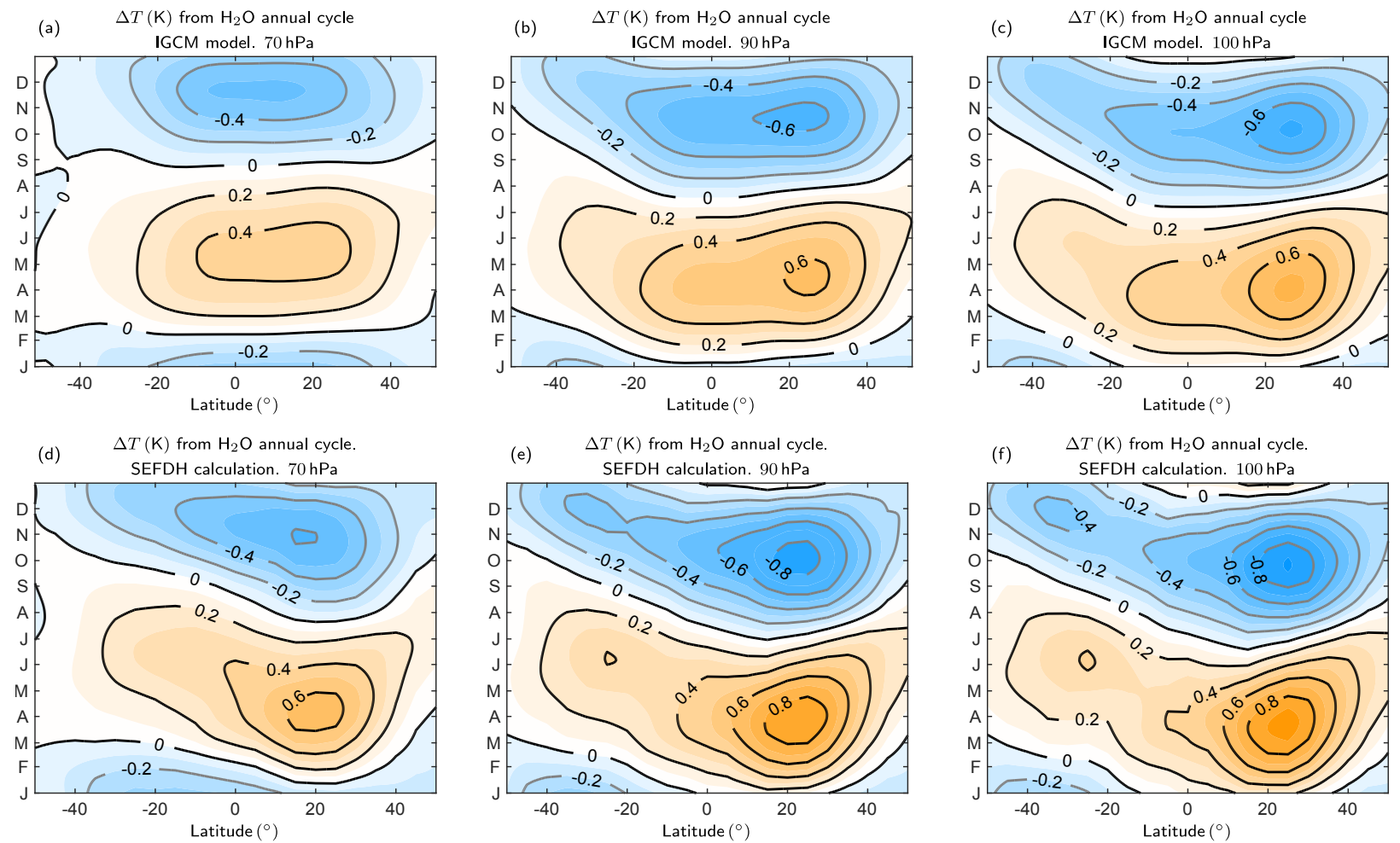

Figure 11. Temperature changes $(\mathrm{K})$ calculated using the idealized dynamical model (IGCM) with an annual cycle in water vapour at (a) $70 \mathrm{hPa}$, (b) $90 \mathrm{hPa}$, and (c) $100 \mathrm{hPa}$. Temperature change from the SEFDH calculation (same as Fig. 5b-d) at (d) $70 \mathrm{hPa}$, (e) $90 \mathrm{hPa}$, and (f) $100 \mathrm{hPa}$ for comparison.

where $a$ the radius of the Earth. (Note that this condition can be rewritten in terms of $\beta=2 \Omega / a$, the gradient of the Coriolis parameter at the Equator.) Since the ratio of $\omega_{\mathrm{a}} / \alpha$ is close to 1 (recall that in Sect. 3, the relevant value of the radiative relaxation time was deduced to be about 40 days), it follows from the latter expression, assuming a vertical scale, $D$, of $4 \mathrm{~km}$, that the dynamical heating response will dominate on latitudinal scales of less than about $2000 \mathrm{~km}$ or $20^{\circ}$.

The $\bar{w}^{*}$ response at $70 \mathrm{hPa}$ to the annual ozone cycle variations is shown in Fig. 10d. Consistent with the dynamical scaling argument, the $\bar{w}^{*}$ field tends to emphasize the smaller latitudinal-scale features in the heating field shown in Fig. 2c, e.g. the two regions of strong cooling near $30^{\circ} \mathrm{S}$ and $10^{\circ} \mathrm{N}$ in January and February and the regions of strong heating at about $20^{\circ} \mathrm{S}$ in September and October and at about $10^{\circ} \mathrm{N}$ in August and September. On the other hand, between these regions there tends to be an oppositely signed dynamical response. We have verified consistency by applying the dynamical heating corresponding to the vertical velocity field shown in Fig. 10d, extracted from the IGCM calculation, as a perturbation heating in an SEFDH calculation using the same procedure described in Sects. 3.3 and 4. The resulting temperature response shown in Fig. 10e is a very good match to the difference in temperature in Fig. 10c and reassures us that the difference between SEFDH and dynamical calcula- tions can indeed be interpreted as resulting from the effect of dynamical heating and is not due to differences in detail in the implementation of the two calculations.

The temperature difference at $70 \mathrm{hPa}$ between the SEFDH and IGCM calculations (Fig. 10c) is, therefore, that forced by a heating anomaly equal to the dynamical heating response. The overall effect of the dynamical adjustment is to smooth the SEFDH-predicted temperature response in latitude, eliminating features of latitudinal scale (in this particular problem) less than about $20^{\circ}$. The amplitude of $\bar{w}^{*}$ between $20^{\circ} \mathrm{N}$ and $20^{\circ} \mathrm{S}$ is typically about $20 \%$ of the amplitude of the annual cycle in upwelling in ERA-Interim, implying that the ozone heating plays a non-negligible role in determining the latitudinal structure of the overall annual cycle in $\bar{w}^{*}$.

\subsection{Temperature response to annual water vapour cycle}

The temperature response of the dynamical model to a perturbation from annual average water vapour to annually varying water vapour is now considered in a similar way to the ozone perturbation just discussed. Given the substantial radiative interactions in the water vapour response between different vertical layers, the temperature responses at each of the levels 70,90 , and $100 \mathrm{hPa}$ are displayed respectively in Fig. 11ac. The corresponding SEFDH temperature responses at 70 , 

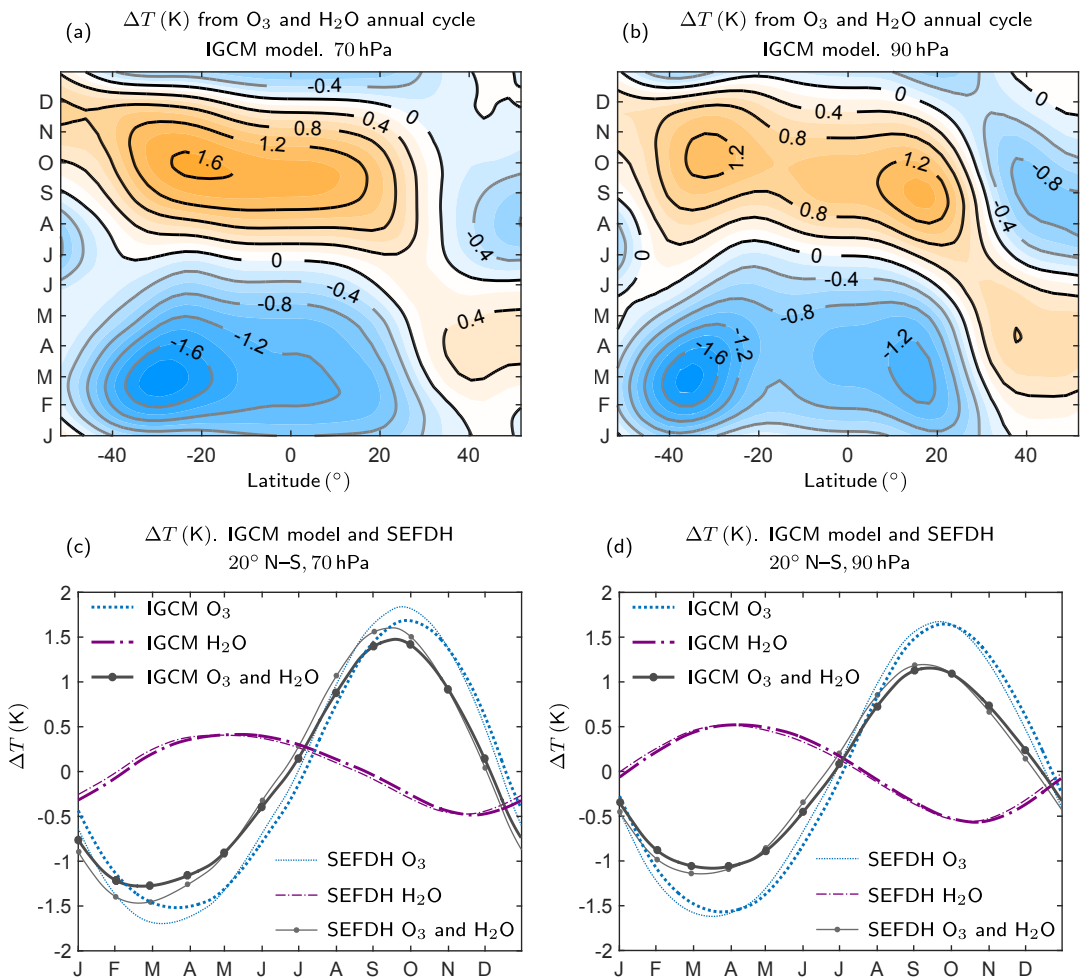

Figure 12. Temperature changes (K) calculated using the idealized dynamical model (IGCM) with annual cycles in both ozone and water vapour shown at (a) $70 \mathrm{hPa}$ and at (b) $90 \mathrm{hPa}$. Temperature changes averaged between $20^{\circ} \mathrm{N}$ and $20^{\circ} \mathrm{S}$ at (c) $70 \mathrm{hPa}$ and (d) $90 \mathrm{hPa}$ and showing the effects of ozone and water vapour in the dynamical model (thick lines) as well as the corresponding SEFDH temperature changes from Fig. 7a and $\mathrm{b}$ (thin lines).

90, and $100 \mathrm{hPa}$ are shown respectively in Fig. 11d, e, and f. As was the case for ozone, the temperature responses in the dynamical model are broader and smoother than the corresponding SEFDH temperature responses. The prominent maxima in heating in March and April at $20^{\circ} \mathrm{N}$ at $70 \mathrm{hPa}$ and about $25^{\circ} \mathrm{N}$ at 90 and $100 \mathrm{hPa}$, and in cooling in September to November at the same locations, are reduced in magnitude, but over the Equator and extending into the SH there is increased heating in March and April and increased cooling in September to November. The resulting structure in the tropics is much more symmetric across the Equator than the SEFDH temperature response.

\subsection{Temperature response to annual ozone and water vapour cycles}

The combined effect of the annual ozone and water vapour cycles in the dynamical calculation is now considered. Their effects, to very good approximation, add up linearly. The latitudinal structure of the combined response is shown for $70 \mathrm{hPa}$ (Fig. 12a) and for $90 \mathrm{hPa}$ (Fig. 12b). Figure 12c and d show the temperature responses in the dynamical model averaged between $20^{\circ} \mathrm{N}$ and $20^{\circ} \mathrm{S}$, to ozone and water vapour individually and their combined response, at 70 and at $90 \mathrm{hPa}$ respectively. Also shown in these figures are the SEFDH re- sults for comparison (same as Fig. 7a and b). By this tropical average measure, there is virtually no change in the peak-topeak amplitudes of the individual and combined temperature responses to ozone and water vapour variations between the SEFDH and dynamical calculations. Any reduction in local latitudinal maxima in the temperature response is offset by the broadening effect, leaving the tropical average essentially the same. However, we reiterate that important changes in the structure of the temperature responses across the tropics occur as a result of including the zonally symmetric dynamical adjustment.

The non-locality in latitude in the dynamical problem means that the temperature response in the tropics, shown in Fig. 12a and b, is potentially determined in part by the change in trace gases in the extratropics. To quantify this effect, we restricted both the annual ozone and water vapour cycle perturbations to the tropical region between $30^{\circ} \mathrm{N}$ and $30^{\circ} \mathrm{S}$. The net effect of the annual variation in trace gases in the extratropics is to increase the amplitude of the temperature response in the tropics from 2.6 to $2.8 \mathrm{~K}$ peak to peak (not shown). The dominant contribution to the annual cycle change in temperature in the tropics is therefore due to ozone and water vapour variations in the tropics. 


\section{Discussion}

We have analysed radiative aspects of the prominent annual cycle in temperature in the TTL and tropical lower stratosphere, which has a maximum peak-to-peak amplitude at $70 \mathrm{hPa}$ of $\sim 8 \mathrm{~K}$. Building on previous work (Chae and Sherwood, 2007; Fueglistaler et al., 2011), we have applied the seasonally evolving fixed dynamical heating (SEFDH) method to calculate the temperature response to the annual cycle variations in zonal mean ozone and water vapour, derived here from the SWOOSH satellite dataset (Davis et al., 2016). We extend the previous work by presenting explicit results for the effects of water vapour variations and by paying particular attention to the vertical structure of the temperature response and the role of variations in the trace gas mixing ratios in different vertical layers. In our first approach, we have used an SEFDH calculation in which the temperature response to annual variations in a trace gas is calculated independently at each latitude, assuming that the dynamical heating at each height is unchanged from its value in a control state in which the trace gas mixing ratios are constant (and equal to their annual mean values).

We find substantial contributions to the peak-to-peak amplitude of the tropical average $\left(20^{\circ} \mathrm{N}-20^{\circ} \mathrm{S}\right)$ annual cycle in temperatures from ozone $(3.5 \pm 0.4 \mathrm{~K}$ at $70 \mathrm{hPa}, 3.3 \pm 0.5 \mathrm{~K}$ at $90 \mathrm{hPa}$, and $2.6 \pm 0.2 \mathrm{~K}$ at $100 \mathrm{hPa}$ ) and from water vapour $(0.9 \pm 0.1 \mathrm{~K}$ at $70 \mathrm{hPa}, 1.1 \pm 0.1 \mathrm{~K}$ at $90 \mathrm{hPa}$, and $1.0 \pm 0.03 \mathrm{~K}$ at $100 \mathrm{hPa}$ ). Whilst the ozone contribution maximizes around $70 \mathrm{hPa}$ and is roughly in phase with the observed annual temperature cycle, the water vapour contribution maximizes around $90 \mathrm{hPa}$ and is of the opposite phase. Despite the cancellation, the net effect of variations in ozone and water vapour together is substantial and amounts to about $35 \%$ of the observed annual cycle at both 70 and $90 \mathrm{hPa}$ and about $45 \%$ at $100 \mathrm{hPa}$ (Fig. 7). Our results are broadly consistent with the recent independent work of Gilford and Solomon (2017).

Further SEFDH calculations showed that in the region where the ozone has the largest temperature change, $70 \mathrm{hPa}$, the ozone-induced temperature variation is caused primarily $(80 \%)$ by local ozone variations (Fig. 3). In contrast, the water-vapour-induced temperature variation is largest at $90 \mathrm{hPa}$ and is caused by both local and non-local water vapour variations. Overall, $60 \%$ of the water-vapour-induced temperature variation at this level comes from water vapour variation in the region 100 to $80 \mathrm{hPa}$ and $40 \%$ from the region 130 to $100 \mathrm{hPa}$ (Fig. 5). This upward non-local radiative effect is seen throughout the lower stratosphere and has important implications for cold point temperatures. For example, if the amplitude of the annual cycle in water vapour below the cold point was to increase, then the radiative effect would reduce the amplitude in the annual cycle in cold point temperatures and hence reduce the amplitude of the annual cycle in water vapour at and above the cold point.
All of the calculations make use of a clear-sky assumption. A rough SEFDH calculation taking into account an estimate of the annual mean climatological high cloud cover shows that the peak-to-peak annual cycle temperature change due to ozone at $70 \mathrm{hPa}$ decreases by $5-10 \%$ at all latitudes between $20^{\circ} \mathrm{N}$ and $20^{\circ} \mathrm{S}$. The effect on the annual water vapour cycle at the same level is negligible. The clouds lead primarily to a reduction in the amount of upwelling longwave radiation reaching $70 \mathrm{hPa}$ of about $0.05 \mathrm{~K} \mathrm{day}^{-1}$, which in turn decreases the ozone temperature response. A full assessment of the cloud effect is beyond the scope of this work and further work is needed to establish its precise contribution.

We also examined the factors controlling the vertical structure of the amplitude of the annual cycle in temperatures. The observed maximum centred on $70 \mathrm{hPa}$ and, largely restricted to the 50 to $100 \mathrm{hPa}$ layer, arises from a combination of several factors. The vertical structure cannot be explained by clear-sky radiative damping timescales alone, which maximize over a deep region, centred near the cold point at $100 \mathrm{hPa}$. However, both the dynamical and radiative forcings maximize above the cold point, and in combination with an inferred upper-tropospheric constraint active below $130 \mathrm{hPa}$, these lead to the observed maximum at $70 \mathrm{hPa}$. We have not attempted to provide an explanation for the inferred upper-tropospheric constraint and highlight this as an area for further study.

Finally, we investigated the effect on the temperature response of relaxing the SEFDH assumption, thereby going beyond the work of Fueglistaler et al. (2011) and Gilford and Solomon (2017). We do this by incorporating the radiative code used for the SEFDH calculations within a 2-D (heightlatitude) dynamical model. Consistent with dynamical expectations, part of the heating associated with annual cycle variations in both ozone and water vapour drives an annual cycle in the upwelling and that may play a non-negligible role in determining the latitudinal structure of the observed annual cycle in upwelling. This has the effect of reducing latitudinal gradients in the SEFDH-predicted temperature response, particularly across the tropics. However, this modification of the response leaves the tropical $\left(20^{\circ} \mathrm{N}-20^{\circ} \mathrm{S}\right)$ average temperature response essentially unchanged. Therefore, the conclusion that the net effect of ozone and water vapour contributes about $35 \%$ of the annual cycle peak-to-peak amplitude at 70 and $90 \mathrm{hPa}$ from the SEFDH calculations is robust to including the dynamical adjustment. The detailed latitudinal structure predicted by the SEFDH calculation, however, is not robust to this adjustment.

As explicitly illustrated by Fig. 10d (for ozone), the differences between the temperature responses to ozone and water vapour calculated through the SEFDH approach and those calculated using the 2-D dynamical model demonstrate that low-latitude temperature features with small latitudinal scales predicted by SEFDH calculations are unlikely to be reproducible when the SEFDH assumption is relaxed because these features will be smoothed out by the dynamical 
response. (When considering annual variations in the TTL, "small latitudinal scales" means less than about $20^{\circ}$ of latitude.) This applies to Figs. $3 \mathrm{~b}$ and $5 \mathrm{~b}-\mathrm{d}$ in this paper, to previous SEFDH calculations of the temperature response to annual variations in ozone (Fueglistaler et al., 2011, their Fig. 5b), and to similar calculations of the effect of recent interannual variations in ozone and water vapour (Gilford et al., 2016, their Fig. 6).

Within the 2-D zonally symmetric dynamical formalism presented here, we do not take account of changes in waveinduced forces. This effect has been discussed by several authors over the last 30 years or so, including Fels et al. (1980) and Garcia (1987), usually making the assumption that the wave force can be represented by Rayleigh friction (so that the local wave force is proportional to and opposite of the local zonal velocity). However, it is generally accepted that Rayleigh friction is a poor representation of the wave forces that operate in the upper troposphere and stratosphere. Ming et al. (2016) analyse the effect of the change in wave force in the response to imposed steady localized zonally symmetric heating in a simple 3-D model (where the waves are resolved and no Rayleigh friction assumption is necessary) and argue that the effect is to broaden the temperature response, particularly at low latitudes. Latitudinal structure in the imposed heating tends to be balanced by the dynamical heating associated with the meridional velocity response, and the change in wave force provides the necessary angular momentum balance. A similar effect is seen in the zonally symmetric problem with Rayleigh friction (e.g. Garcia, 1987, their Fig. 6). There is an analogous effect in the time-dependent zonally symmetric response problem, without any change in wave force or Rayleigh friction, considered in Sect. 5, with the angular momentum balance including the zonal acceleration. Therefore, the effect of including the change in wave force in the dynamical problem is, broadly speaking, expected to be similar; in addition to that already seen in the time-dependent zonally symmetric problem, at low latitudes, the dynamical adjustment will smooth the temperature response to latitudinally varying heating. If the change in wave force is weak then the additional effect will be small. If the change in wave force is strong then the result will be that the smoothing is over a larger range of latitudes. The fact that the observed annual cycle in temperature is coherent over the latitude range $20^{\circ} \mathrm{N}-20^{\circ} \mathrm{S}$ (Fig. $1 \mathrm{~b}-\mathrm{d}$ ), but no more than that, suggests that the wave force effect cannot be too strong. Therefore, we ex- pect that our conclusions from the zonally symmetric dynamical problem studied here would not be changed too much if the change in wave force was included. Furthermore, we expect that similar dynamical principles will allow extension to the fully three-dimensional case, implying that an SEFDH calculation will have limited ability to predict geographical (i.e. latitudinal and longitudinal) variations in temperature resulting from geographical latitudinal variations in radiatively active gases or in other relevant quantities such as clouds or aerosol.

Current comprehensive global (chemistry-)climate models show a large spread in the amplitude of the TTL annual cycle in temperature (e.g. Kim et al., 2013), but the quantitative causes of these differences are not well understood. The results of this study show that an erroneous representation of the climatology of ozone and water vapour, as is commonplace amongst such models (e.g. Gettelman et al., 2010), is likely to be a major contributor to poor model performance for capturing the TTL annual temperature cycle. Similar conclusions are likely to apply to interannual variations, e.g. in the 2010-2013 period investigated by Gilford et al. (2016) using SEFDH calculations. Progress in improving the representation of the TTL in comprehensive global models therefore requires consideration of the coupling through transport and radiative effects between dynamics, ozone, and water vapour in the TTL. Specific aspects highlighted by our results include a strong sensitivity of ozone radiative effects to mean ozone mixing ratios in the 90 to $70 \mathrm{hPa}$ region, for which models with interactive chemistry simulate a range of values (Gettelman et al., 2010) and for which a range of observation-based gridded datasets exist for climate models that do not include chemistry (Cionni et al., 2011; Bodeker et al., 2013). Furthermore, because of the importance shown here of non-local radiative effects for water vapour in the TTL, modelled cold point temperatures are also likely to be sensitive to the representation of water vapour mixing ratios in the upper tropical troposphere.

Data availability. The ERA-Interim dataset is described in Dee et al. (2011) and available from http://apps.ecmwf.int/datasets/data/ interim-full-daily/. The SWOOSH dataset is described in Davis et al. (2016) and available at Davis and Rosenlof (2016). 


\section{Appendix A: FDH calculations}

A first-order estimate of the effect of specified perturbations to radiative trace gases on temperatures in the TTL and the stratosphere can be made using a fixed dynamical heating (FDH) calculation where it is assumed that the dynamical heating remains constant from the unperturbed to the perturbed state, i.e. that no changes in circulation occur as a result of the perturbation (Fels et al., 1980; Ramanathan and Dickinson, 1979). The timescale for stratospheric adjustment to the perturbation is essentially the stratospheric radiative damping time. This is about 40 days in the tropical lower stratosphere and less than a week near the stratopause, although different techniques estimate different values and furthermore the timescale is dependent on the vertical scale of the heating perturbation (e.g. Dickinson, 1973; Mlynczak et al., 1999; Hitchcock et al., 2010). These stratospheric timescales are relatively short compared to that required for tropospheric temperatures to adjust to the perturbation because these are strongly constrained to surface temperatures, which particularly in oceanic regions, will evolve only on timescales of months or years. Hence, in FDH calculations, temperatures are held fixed below some level, often corresponding to the (radiative) tropopause. We choose this level to be $130 \mathrm{hPa}$, consistent with previous calculations. The reasons for this choice are justified in Sect. 3.

The FDH calculation is a simplified version of the SEFDH calculations and the equations below can be compared to Eqs. (2) and (3). Given the background profiles of temperatures and mixing ratios of trace gases $\left(\bar{T}_{0}, \bar{\chi}_{\mathrm{O}_{3}}^{0}, \bar{\chi}_{\mathrm{H}_{2} \mathrm{O}}^{0}\right)$, the dynamical heating, $\bar{Q}_{\text {dyn }}^{0}$, is first calculated by assuming the balance

$\bar{Q}_{\mathrm{rad}}\left(\bar{T}^{0}, \bar{\chi}_{\mathrm{O}_{3}}^{0}, \bar{\chi}_{\mathrm{H}_{2} \mathrm{O}}^{0}\right)+\bar{Q}_{\mathrm{dyn}}^{0}=0$.

The dynamical heating is not a function of time, unlike in the SEFDH calculations. A perturbation is then applied to trace gas mixing ratios $\left(\Delta \bar{\chi}_{\mathrm{O}_{3}}, \Delta \bar{\chi}_{\mathrm{H}_{2} \mathrm{O}}\right)$ and the equilibrium temperature state, $\bar{T}^{0}+\Delta \bar{T}$, is obtained from

$$
\begin{aligned}
& \bar{Q}_{\mathrm{rad}}\left(\bar{T}^{0}+\Delta \bar{T}, \bar{\chi}_{\mathrm{O}_{3}}^{0}+\Delta \bar{\chi}_{\mathrm{O}_{3}}, \bar{\chi}_{\mathrm{H}_{2} \mathrm{O}}^{0}+\Delta \bar{\chi}_{\mathrm{H}_{2} \mathrm{O}}\right) \\
& \quad+\bar{Q}_{\mathrm{dyn}}^{0}=0 .
\end{aligned}
$$

Time-averaged profiles of ozone and water vapour from the SWOOSH dataset and the annual mean temperature from ERA-Interim at the Equator are used as the base profile, and the trace gases are then perturbed. The calculation is done at the Equator on 1 January and the albedo is set to 0.085 . The 100 pressure levels used in all radiative calculations are 1,2, $3,4,5,6,7,8,9,10,11,12,13,14,15,16,17,18,19,20$, $22,25,27,30,35,40,45,50,55,60,65,70,75,80,85,90$, $93,95,97,100,103,105,107,110,113,115,117,120,123$, $125,127,130,133,135,137,140,145,150,155,160,165$, $170,175,180,185,190,200,205,210,215,220,225,230$,
$235,240,245,250,255,260,265,270,275,280,285,290$, $295,300,320,330,340,350,370,400,450,500,600,700$, 800,900 , and $1000 \mathrm{hPa}$.

Numerically, the FDH calculation is done by iterating the temperatures forward with a time step of 1 day using the longwave heating rates to find the new equilibrium temperature. The values are considered to have converged when the temperature change and the fluxes between pressure levels after consecutive time steps fall below $5 \times 10^{-4} \mathrm{~K}$ and $1 \times 10^{-7} \mathrm{~K} \mathrm{~m}^{-1}$ respectively. In practice, these thresholds are reached after about 500 days, which is much larger than any radiative timescales in the stratosphere; hence, they ensure that the temperatures in the stratosphere have converged.

In Sects. A1 and A2 below, we describe in detail the temperature response to example perturbations in ozone and in water vapour. These provide helpful background for understanding the response to the annual cycle in these two gases reported in Sect. 3.

\section{A1 Ozone perturbation}

The example perturbation applied to ozone mixing ratios is a reduction in mixing ratios in the lower stratosphere (solid line in Fig. A1a, left). This is a simple representation of lower-stratospheric mixing ratios in $\mathrm{NH}$ winter, relative to the annual mean. The perturbation is a Gaussian of the form $A_{0} \exp \left[-0.5((z-18.6) / 2)^{2}\right]$, where $A_{0}=-0.07$ (ppmv) and $z=-7 \log \left(p / 1 \times 10^{5}\right) \mathrm{km}$. Removing ozone in the lower stratosphere leads to an instantaneous local decrease in the longwave and shortwave heating (Fig. A1a, right) and results in a local decrease in the temperature in an FDH calculation (Fig. A1b, where "local" refers to the vertical region in which the perturbation in mixing ratios is applied).

The time evolution of various components of the longwave radiative heating after the perturbation is applied is shown in Fig. A1b, c, d, and e; these show respectively total longwave heating and then the individual contributions from ozone, carbon dioxide, and water vapour. The instantaneous effect of the reduction in ozone mixing ratios is to cause a decrease in both the shortwave heating and the local longwave heating because of a reduction in local longwave absorption. The shortwave change, which has peak amplitude $-1.1 \times 10^{-2} \mathrm{~K} \mathrm{day}^{-1}$, occurs because of reduced shortwave absorption and is essentially proportional to the local change in mixing ratio. The instantaneous longwave change is significantly larger, with peak amplitude of $-4 \times 10^{-2} \mathrm{~K} \mathrm{day}^{-1}$, and, in addition to the local decrease, there is an increase, with similar peak amplitude in the region above the mixing ratio perturbation (see Fig. A1d). The explanation for this vertical structure is that, because ozone mixing ratios are small in the troposphere, in the lower stratosphere there is a substantial upwelling flux of longwave radiation of wavelength relevant to ozone ( $9.6 \mu \mathrm{m}$-band), and the imposed perturbation in ozone mixing ratios leads to less local absorption 

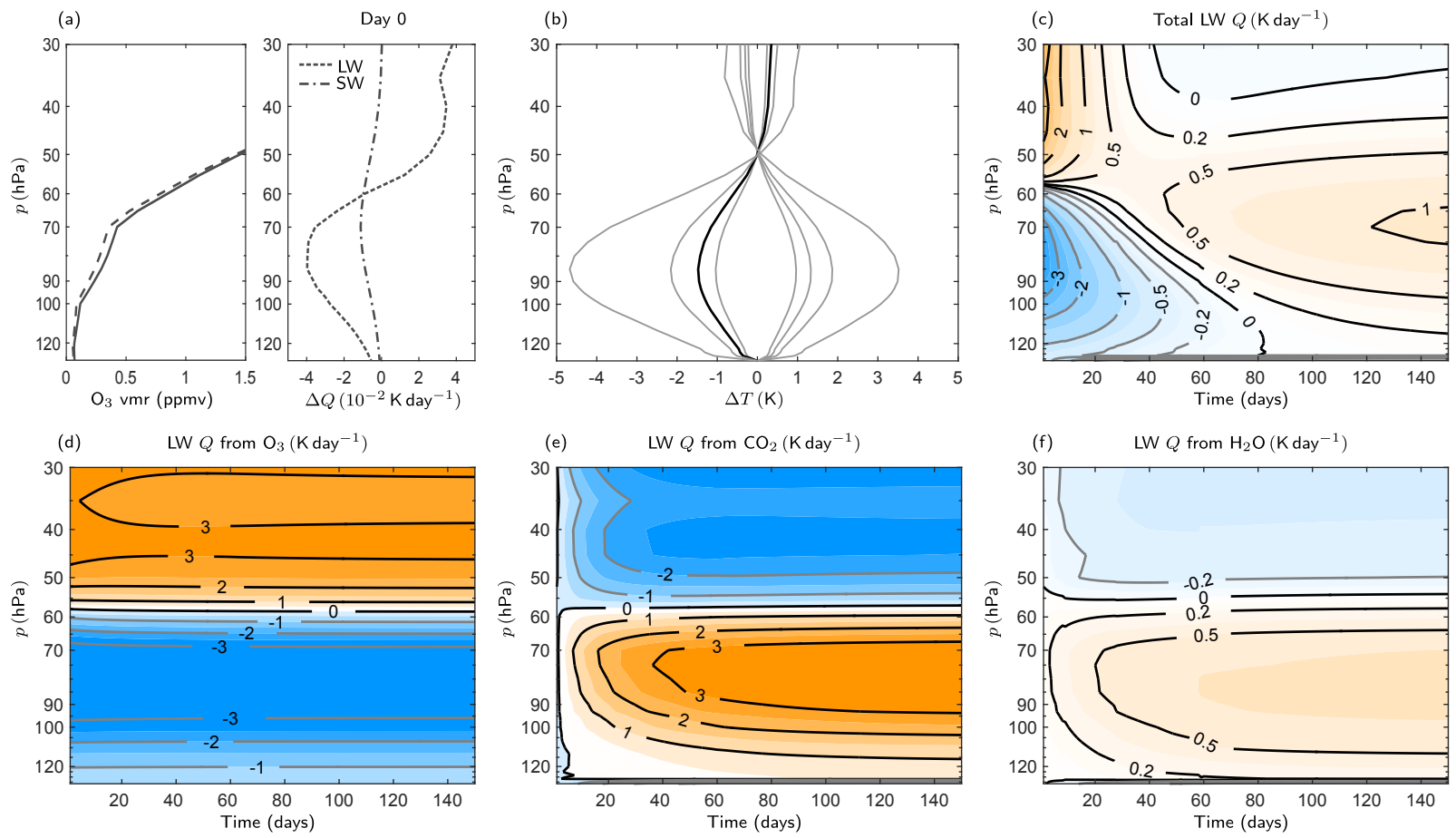

Figure A1. (a) Left: ozone reference profile (solid) and perturbed profile (dashed) used in the FDH calculation. Right: instantaneous change in heating rate from perturbation. (b) Temperature change resulting from the ozone perturbation. The calculation is done at the Equator on 1 January. The lines correspond to perturbations of $A_{0}=-0.2,-0.1,-0.07$ (black line), $-0.05,0.05,0.07,0.1$, and 0.2 ppmv from left to right at the maximum temperature change (see text for more details). For the perturbation of -0.07 ppmv, (c) shows total longwave heating rate from all the constituents, (d) longwave heating rate due to ozone, (e) longwave heating rate due to carbon dioxide, and (f) longwave heating rate due to water vapour.

of this upwelling radiation with correspondingly increased absorption above the perturbation. Note that another potential effect of the perturbation to ozone mixing ratios is reduced local emission, which would imply local heating. Figure A1d shows that any effect of change in emission is dominated by the changed absorption of upwelling radiation.

In the response to the instantaneous change in heating just described, the temperature and hence the longwave fluxes change, with both carbon dioxide (Fig. Ale) and to a lesser extent water vapour (Fig. A1f) contributing significantly. Note that changes in the ozone longwave heating, after the instantaneous change resulting from the perturbation to ozone mixing ratios, are weak, suggesting that it plays little role in the temperature adjustment. An equilibrium is reached where the net longwave heating (Fig. A1c) balances the reduction in shortwave heating. The equilibrium temperature change is dominated by a local decrease centred on $70 \mathrm{hPa}$ (i.e. the centre of the region where ozone mixing ratios were perturbed). Several timescales are involved in the adjustment process and Fig. A1c shows that the heating rates and hence the temperature are still evolving after 100 days. This justifies the use of an SEFDH rather than an FDH calculation when studying the annual cycle in temperatures.
Further experiments show that the FDH temperature response varies approximately linearly with the peak value of the Gaussian perturbation in the range -0.1 to $0.1 \mathrm{ppmv}$ (thin grey lines in Fig. A1b), so that the detailed time evolution described above continues to hold if heating and temperature anomalies are multiplied by the appropriate factor. In particular a modest increase in ozone mixing ratios will lead to a local temperature increase, in which the net (negative) change in longwave heating balances an increase in shortwave heating. For mixing ratio anomalies with peak values of $\pm 0.2 \mathrm{pmmv}$, substantial non-linear effects appear.

\section{A2 Water vapour perturbation}

Following the approach in Appendix A1 above, a corresponding calculation is now described in which water vapour is perturbed by removing a Gaussian of the form $\left.B_{0} \exp \left[-0.5((z-16.9) / 1.5)^{2}\right)\right]$, where $B_{0}=$ 1.0 (ppmv) (Fig. A2a, left) which leads to an instantaneous local decrease in the shortwave and a local increase in the longwave radiation (Fig. A2a, right). This is also a very simple representation of lower-stratospheric mixing ratios in $\mathrm{NH}$ winter, relative to the annual mean. As in Appendix A1, Fig. A2c, d, e, and f respectively show the total longwave heating and then the individual contributions from ozone, 

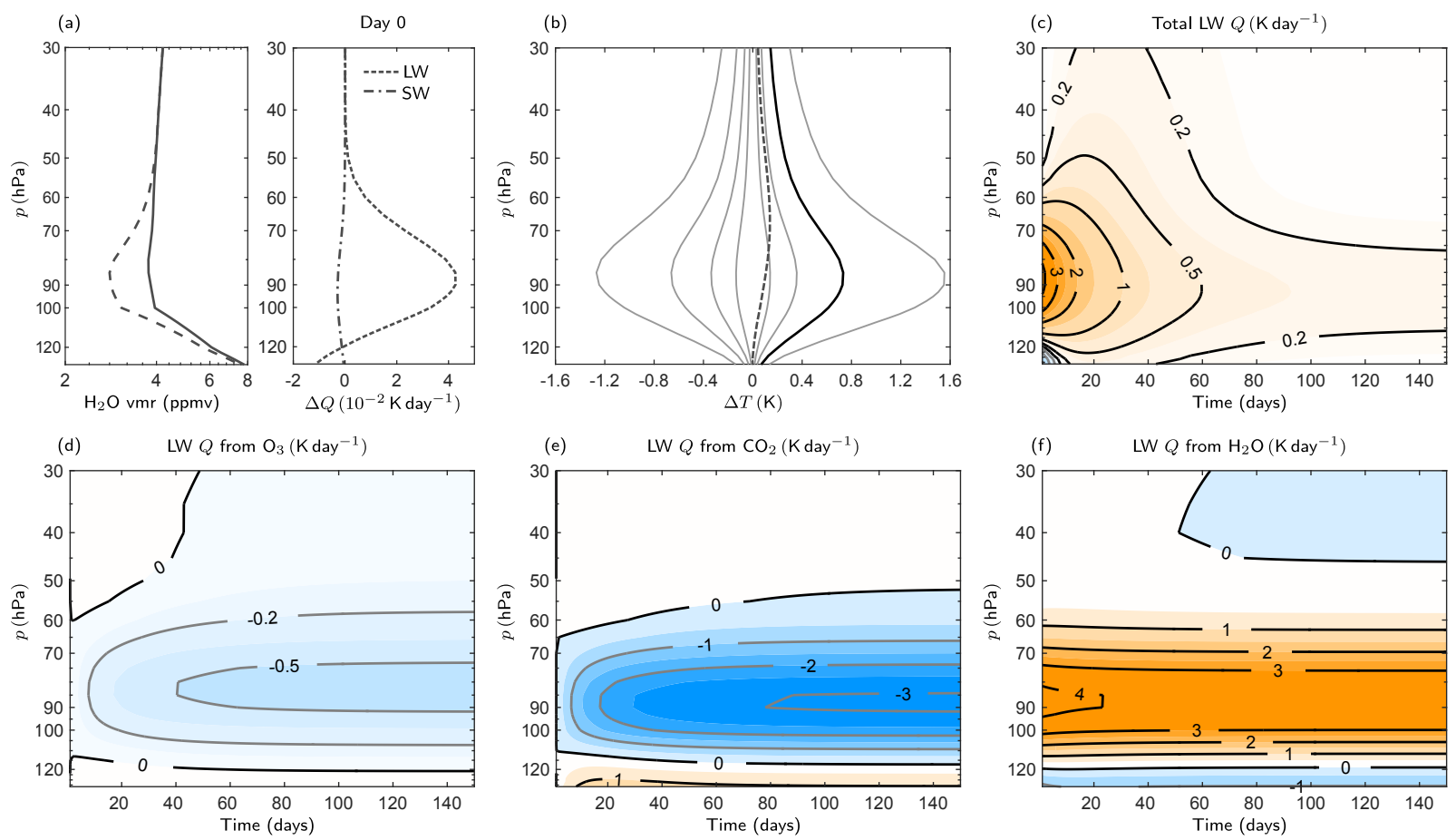

Figure A2. Similar to the plots in Fig. A1 but for water vapour. (a) Left: water vapour profile (solid) and perturbation (dashed) used in the FDH calculation. Right: instantaneous change in heating rate from perturbation. (b) Temperature change resulting from the water vapour perturbation for $B_{0}=2.0,1.0,0.5,0.2,-0.2,-0.5,-1.0$ (thick black line), and $-2.0 \mathrm{ppmv}$ from left to right at the maximum temperature change for the solid lines. For comparison, a perturbation in water vapour of a similar form to the ozone perturbation with $A_{0}=0.2$ ppmv is also included (dashed grey line) (see text for more details). For the perturbation $B_{0}=-1.0 \mathrm{ppmv}$, (c) is total longwave heating rate from all the constituents, (d) is longwave heating rate due to ozone, (e) is longwave heating rate due to carbon dioxide, and (f) is longwave heating rate due to water vapour.

carbon dioxide, and water vapour during the evolution in response to the water vapour perturbation.

The abundance of water vapour in the troposphere means it is relatively opaque to upwelling longwave radiation in the main water vapour absorption bands. This means that, in contrast to ozone, the dominant instantaneous effect in the longwave of locally reducing the water vapour in the lower stratosphere is to cause less local emission, i.e. local heating, and, correspondingly, less non-local absorption in neighbouring regions, i.e. non-local cooling, rather than any effect on the absorption of upwelling radiation. This can be seen in the water vapour longwave heating shown in Fig. A2f. Note that the change in non-local absorption is seen primarily in the upper troposphere below the region where the mixing ratios are reduced because background water vapour mixing ratios are relatively large there compared to those in the stratosphere. The reduction in water vapour mixing ratio also leads to a reduction in shortwave absorption, as was the case for ozone, but the magnitude $\left(-0.3 \times 10^{-2} \mathrm{~K} \mathrm{day}^{-1}\right)$ is smaller than the corresponding change in longwave heating $\left(4.3 \times 10^{-2} \mathrm{~K} \mathrm{day}^{-1}\right)$.

In the evolution following the initial instantaneous change in heating, the longwave heating contributions due to car- bon dioxide, water vapour, and ozone all play a role to limit the temperature response and redistribute it in the vertical (Fig. A2d-f). In particular the initial local increase in temperatures is transmitted in the vertical through longwave fluxes in the carbon dioxide bands to give subsequent temperature increases substantially above the layer in which water vapour mixing ratios were perturbed. This sort of behaviour is not captured by a local Newtonian cooling approximation. As was the case for ozone, the longwave heating (and hence the temperatures) continue to evolve beyond 100 days. This suggests that a sequence of quasi-steady FDH calculations would be inadequate for studying the annual cycle in temperatures and again justifies the use of the SEFDH approach.

Experiments with different amplitudes of perturbation to water vapour mixing ratio (Fig. 19b) show that the response is linear for peak values up to $\pm 1.0 \mathrm{ppmv}$, with non-linear effects visible at \pm 2.0 ppmv. Note that a similar amplitude and shape of perturbation as the ozone perturbation with $A_{0}=0.2$ ppmv are shown for comparison as a dashed grey line in Fig. A2b and the magnitude of the temperature change is small $(0.14 \mathrm{~K}$ at $70 \mathrm{~K})$ compared to that for the equivalent ozone perturbation $(2.8 \mathrm{~K}$ at $70 \mathrm{~K})$. 


\section{Appendix B: Statistical methods}

Estimates of the $95 \%$ confidence intervals are shown for the SEFDH calculations in Fig. 7. For ozone and water vapour in the SWOOSH dataset, a combined uncertainty arising from the uncertainties in the various instruments and a standard deviation arising from interannual variability can be obtained. These two quantities are provided as part of the SWOOSH dataset and are of similar magnitude in the region of interest. A $95 \%$ confidence interval is obtained for each month by summing these two uncertainties in quadrature and assuming that each year in the dataset is independent. This assumption has been checked and is adequate. The uncertainty is dominated by the interannual variability for ozone. The SEFDH calculation for each constituent is then repeated to give bounds for the temperature change given the uncertainty in that constituent only. For example, the water vapour uncertainty in Fig. 7 is small and only reflects that coming from the water vapour dataset and not from differences in ozone, which will also affect the temperature change from water vapour. However, the combined effect of both uncertainties is present in the calculation of the temperature change from both ozone and water vapour. When calculating the peak-topeak amplitude, the uncertainties at the maximum amplitude and minimum amplitude are added in quadrature.
The residual mean vertical velocity in reanalysis datasets has a large interannual variability and this is the only source of uncertainty taken into account in the calculation in Fig. 7. Again, in estimating this quantity, we assume that each year of the dataset is independent. This leads to a peak-to-peak amplitude from the dynamical heating averaged over $20^{\circ} \mathrm{N}-$ $20^{\circ} \mathrm{S}$ at $70 \mathrm{hPa}$ of $5.6 \pm 0.6 \mathrm{~K}$ and of $1.5 \pm 0.6 \mathrm{~K}$ at $90 \mathrm{hPa}$. In addition, there are other large discrepancies in estimates of the dynamical heating which are not taken into account in this calculation. For example, the difference between calculating the dynamical heating directly from $\bar{w}^{*} \bar{S}$ and from the thermodynamic equation can be as high as about $40 \%$ in certain months. A full treatment of all the sources of uncertainty in this calculation is beyond the scope of this work. 


\section{Appendix C: Background ozone mixing ratio}

The greatest sensitivity of the temperature changes calculated in the SEFDH calculations is to the background value of ozone. A set of illustrative SEFDH calculations is presented below to show how this affects the temperature change for the annual ozone cycle. Figure C1a shows an illustrative perturbation (third line from the left, solid grey) to the annual mean ozone profile (middle line, solid black) used in the SEFDH calculations in Sect. 3.1. (The illustrative perturbation is calculated as a decrease of twice the standard deviation of the sample mean, $\hat{\sigma}_{\mu}=\hat{s} \hat{n}_{e}{ }^{-1 / 2}$, where $\hat{s}$ is the standard deviation of the time series of annual mean values in the SWOOSH dataset and $\hat{n}_{e}$ is the effective number of degrees of freedom in this time series. This method is used to obtain a sensible ozone perturbation.) This decrease in the annual mean ozone leads to an increase in the peak-to-peak amplitude of the temperature change due to ozone at $70 \mathrm{hPa}$ by about $0.16 \mathrm{~K}$ (Fig. C1b). Similarly, an increase in the annual mean ozone leads to a smaller-amplitude ozone annual cycle. Further experiments show that the change in the peakto-peak amplitude varies roughly linearly with the change in the background ozone mixing ratio within the range of values shown in Fig. C1a. These values are of a magnitude comparable to those seen in other ozone datasets. For instance, Tummon et al. (2015) quote a spread of about $\pm 10 \%$ in the annual mean ozone in the lower stratosphere between seven newly available merged satellite ozone profile datasets. The spread in individual satellite instruments is larger with differences of up to $\pm 20 \%$ from the multi-instrument mean (Tegtmeier et al., 2013).

Figure $\mathrm{C} 1 \mathrm{c}$ shows the contribution from different pressure ranges to the change in the annual temperature cycle from the illustrative perturbation. A decrease in the annual mean ozone increases the upwelling longwave radiation reaching $70 \mathrm{hPa}$ leading to a larger annual temperature cycle response at $70 \mathrm{hPa}$. This can be seen from the largest contributions coming from the regions 90 to $70 \mathrm{hPa}$ and below $90 \mathrm{hPa}$. (a)

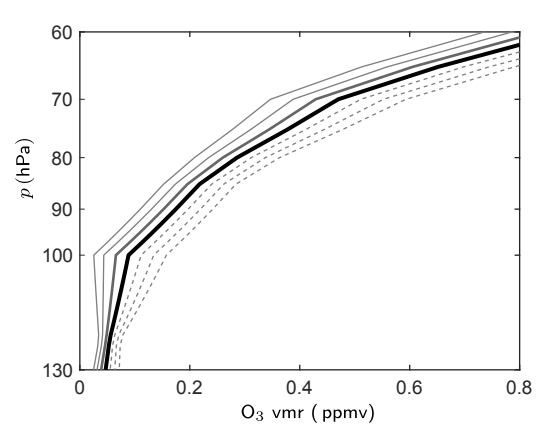

(b)

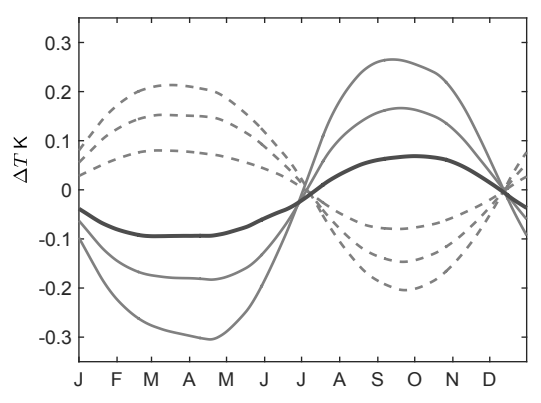

(c)

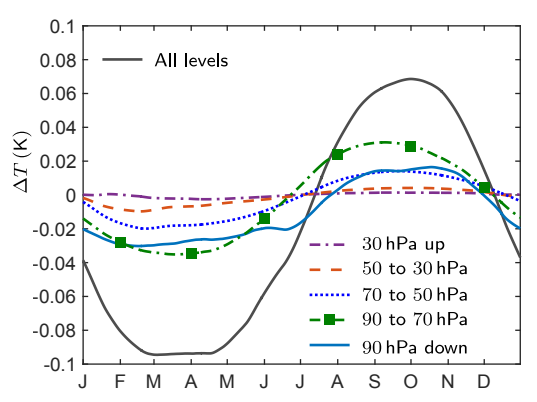

Figure C1. (a) Annual mean ozone profile averaged between $20^{\circ} \mathrm{N}$ and $20^{\circ} \mathrm{S}$ (middle solid black line). Solid dark grey line to the left of the middle line shows an illustrative perturbation to the annual mean profile where the ozone background value is decreased. Solid grey lines represent negative perturbations 2 times and 3 times this perturbation. Corresponding positive perturbations are shown as dashed lines. (b) Difference to the SEFDH temperature change at $70 \mathrm{hPa}$ for the annual ozone cycle due to the different annual mean ozone values in (a). The darker solid grey line shows the temperature change for the illustrative perturbation. The lighter grey lines and dashed lines correspond to the increasingly larger negative and positive perturbations respectively, as shown in (a). (c) The contribution of different ranges of pressure levels to the temperature change for the illustrative perturbation. 
Competing interests. The authors declare that they have no conflict of interest.

Acknowledgements. The authors wish to thank Stephan Fueglistaler for helpful discussions, Manoj Joshi for assistance with the IGCM3.1 model, and Sean Davis and Karen Rosenlof for help with the SWOOSH dataset. We also acknowledge helpful comments from the two referees. Alison Ming, Amanda C. Maycock, and Peter Hitchcock were supported by an ERC ACCI grant (project no. 267760). In addition, Amanda C. Maycock was supported by an AXA Postdoctoral Research Fellowship and a NERC Research Fellowship (grant NE/M018199/1), and Peter Hitchcock was supported by an NSERC postdoctoral fellowship. Peter Haynes acknowledges support from the IDEX Chaires d'Attractivité programme of l'Université Fédérale de Toulouse, Midi-Pyrénées.

Edited by: Q. Fu

Reviewed by: S. Solomon and one anonymous referee

\section{References}

Andrews, D. G., Holton, J. R., and Leovy, C. B.: Middle atmosphere dynamics, Academic Press, Orlando, 1987.

Bodeker, G. E., Hassler, B., Young, P. J., and Portmann, R. W.: A vertically resolved, global, gap-free ozone database for assessing or constraining global climate model simulations, Earth Syst. Sci. Data, 5, 31-43, doi:10.5194/essd-5-31-2013, 2013.

Bresser, G., Manning, A. J. L., Pawson, S., and Rodgers, C. D.: A New Parameterization of Scale-Dependent Radiative Rates in the Stratosphere, J. Atmos. Sci., 52, 4429-4447, doi:10.1175/15200469(1995)052<4429:ANPOSD>2.0.CO;2, 1995.

Bruhl, C., Drayson, S. R., Russell, J. M., Crutzen, P. J., McInerney, J. M., Purcell, P. N., Claude, H., Gernandt, H., McGee, T. J., McDermid, I. S., and Gunson, M. R.: Halogen occultation experiment ozone channel validation, J. Geophys. Res., 101, 1021710240, doi:10.1029/95JD02031, 1996.

Chae, J. H. and Sherwood, S. C.: Annual temperature cycle of the tropical tropopause: A simple model study, J. Geophys. Res., 112, D19111, doi:10.1029/2006JD007956, 2007.

Cionni, I., Eyring, V., Lamarque, J. F., Randel, W. J., Stevenson, D. S., Wu, F., Bodeker, G. E., Shepherd, T. G., Shindell, D. T., and Waugh, D. W.: Ozone database in support of CMIP5 simulations: results and corresponding radiative forcing, Atmos. Chem. Phys., 11, 11267-11292, doi:10.5194/acp-11-11267-2011, 2011.

Davis, S. and Rosenlof, K.: NOAA ESRL (2016): Stratospheric Water and OzOne Satellite Homogenized (SWOOSH), Version 2. NOAA National Centers for Environmental Information (NCEI), doi:10.7289/V5TD9VBX, 2016.

Davis, S. M., Rosenlof, K. H., Hassler, B., Hurst, D. F., Read, W. G., Vömel, H., Selkirk, H., Fujiwara, M., and Damadeo, R.: The Stratospheric Water and Ozone Satellite Homogenized (SWOOSH) database: a long-term database for climate studies, Earth Syst. Sci. Data, 8, 461-490, doi:10.5194/essd-8-461-2016, 2016.

de F. Forster, P. M., Blackburn, M., Glover, R., and Shine, K. P.: An examination of climate sensitivity for idealised climate change experiments in an intermediate general circulation model, Clim. Dynam., 16, 833-849, doi:10.1007/s003820000083, 2000.

Dee, D. P., Uppala, S. M., Simmons, A. J., Berrisford, P., Poli, P., Kobayashi, S., Andrae, U., Balmaseda, M. A., Balsamo, G., Bauer, P., Bechtold, P., Beljaars, A. C. M., van de Berg, L., Bidlot, J., Bormann, N., Delsol, C., Dragani, R., Fuentes, M., Geer, A. J., Haimberger, L., Healy, S. B., Hersbach, H., Hólm, E. V., Isaksen, L., Kållberg, P., Köhler, M., Matricardi, M., McNally, A. P., Monge-Sanz, B. M., Morcrette, J.-J., Park, B.-K., Peubey, C., de Rosnay, P., Tavolato, C., Thépaut, J.-N., and Vitart, F.: The ERA-Interim reanalysis: configuration and performance of the data assimilation system, Q. J. Roy. Meteor. Soc., 137, 553-597, doi:10.1002/qj.828, 2011 (data available at: http://apps.ecmwf.int/datasets/data/interim-full-daily/).

Dickinson, R. E.: Method of parameterization for infrared cooling between altitudes of 30 and 70 kilometers, J. Geophys. Res., 78, 4451-4457, doi:10.1029/JC078i021p04451, 1973.

Fels, S. B.: A Parameterization of Scale-Dependent Radiative Damping Rates in the Middle Atmosphere, J. Atmos. Sci., 39, 1141-1152, 1982.

Fels, S. B., Mahlman, J. D., Schwarzkopf, M. D., and Sinclair, R. W.: Stratospheric Sensitivity to Perturbations in Ozone and Carbon Dioxide: Radiative and Dynamical Response, J. Atmos. Sci., 37, 2265-2297, doi:10.1175/15200469(1980)037<2265:SSTPIO>2.0.CO;2, 1980.

Folkins, I., Bernath, P., Boone, C., Lesins, G., Livesey, N., Thompson, A. M., Walker, K., and Witte, J. C.: Seasonal cycles of $\mathrm{O}_{3}$, $\mathrm{CO}$, and convective outflow at the tropical tropopause, Geophys. Res. Lett., 33, 1-5, doi:10.1029/2006GL026602, 2006.

Forster, P. M. D. F. and Shine, K. P.: Assessing the climate impact of trends in stratospheric water vapor, Geophys. Res. Lett., 29, 1086, doi:10.1029/2001GL013909, 2002.

Forster, P. M. F., Freckleton, R. S., and Shine, K. P.: On aspects of the concept of radiative forcing, Clim. Dynam., 13, 547-560, doi:10.1007/s003820050182, 1997.

Fueglistaler, S. and Haynes, P. H.: Control of interannual and longer-term variability of stratospheric water vapor, J. Geophys. Res.-Atmos., 110, 1-14, doi:10.1029/2005JD006019, 2005.

Fueglistaler, S., Bonazzola, M., Haynes, P., and Peter, T.: Stratospheric water vapor predicted from the Lagrangian temperature history of air entering the stratosphere in the tropics, J. Geophys. Res., 110, D08107, doi:10.1029/2004JD005516, 2005.

Fueglistaler, S., Dessler, A. E., Dunkerton, T. J., Folkins, I., Fu, Q., and Mote, P. W.: Tropical tropopause layer, Rev. Geophys., 47, 1-31, doi:10.1029/2008RG000267, 2009.

Fueglistaler, S., Haynes, P. H., and Forster, P. M.: The annual cycle in lower stratospheric temperatures revisited, Atmos. Chem. Phys., 11, 3701-3711, doi:10.5194/acp-11-3701-2011, 2011.

Garcia, R. R.: On the Mean Meridional Circulation of the Middle Atmosphere, J. Atmos. Sci., 44, 3599-3609, doi:10.1175/15200469(1987)044<3599:OTMMCO>2.0.CO;2, 1987.

Gettelman, A., Hegglin, M. I., Son, S.-W., Kim, J., Fujiwara, M., Birner, T., Kremser, S., Rex, M., Añel, J. A., Akiyoshi, H., Austin, J., Bekki, S., Braesike, P., Brühl, C., Butchart, N., Chipperfield, M., Dameris, M., Dhomse, S., Garny, H., Hardiman, S. C., Jöckel, P., Kinnison, D. E., Lamarque, J. F., Mancini, E., Marchand, M., Michou, M., Morgenstern, O., Pawson, S., Pitari, G., Plummer, D., Pyle, J. A., Rozanov, E., Scinocca, J., Shepherd, T. G., Shibata, K., Smale, D., Teyssèdre, H., and Tian, W.: Mul- 
timodel assessment of the upper troposphere and lower stratosphere: Tropics and global trends, J. Geophys. Res., 115, 1-22, doi:10.1029/2009JD013638, 2010.

Gilford, D. M. and Solomon, S.: Radiative effects of stratospheric seasonal cycles in the tropical upper troposphere and lower stratosphere, J. Climate, 30, 2769-2783, doi:10.1175/JCLI-D16-0633.1, 2017.

Gilford, D. M., Solomon, S., and Portmann, R. W.: Radiative Impacts of the 2011 Abrupt Drops in Water Vapor and Ozone in the Tropical Tropopause Layer, J. Climate, 29, 595-612, doi:10.1175/JCLI-D-15-0167.1, 2016.

Hardiman, S. C., Boutle, I. A., Bushell, A. C., Butchart, N., Cullen, M. J. P., Field, P. R., Furtado, K., Manners, J. C., Milton, S. F., Morcrette, C., O'Connor, F. M., Shipway, B. J., Smith, C., Walters, D. N., Willett, M. R., Williams, K. D., Wood, N., Abraham, L. N., Keeble, J., Maycock, A. C., Thuburn, J., and Woodhouse, M. T.: Processes controlling tropical tropopause temperature and stratospheric water vapor in climate models, J. Climate, 28, 6516-6535, doi:10.1175/JCLI-D-15-0075.1, 2015.

Harries, J. E., Iii, J. M. R., Tuck, A. F., Gordley, L. L., Purcell, P., Stone, K., Bevilacqua, R. M., and Traub, W. A.: Validation of measurements of water vapour from the Halogen Occulatation Experiment (HALOE), J. Geophys. Res., 101, 10205-10216, 1996.

Harris, N. R. P., Hassler, B., Tummon, F., Bodeker, G. E., Hubert, D., Petropavlovskikh, I., Steinbrecht, W., Anderson, J., Bhartia, P. K., Boone, C. D., Bourassa, A., Davis, S. M., Degenstein, D., Delcloo, A., Frith, S. M., Froidevaux, L., Godin-Beekmann, S., Jones, N., Kurylo, M. J., Kyrölä, E., Laine, M., Leblanc, S. T., Lambert, J.-C., Liley, B., Mahieu, E., Maycock, A., de Mazière, M., Parrish, A., Querel, R., Rosenlof, K. H., Roth, C., Sioris, C., Staehelin, J., Stolarski, R. S., Stübi, R., Tamminen, J., Vigouroux, C., Walker, K. A., Wang, H. J., Wild, J., and Zawodny, J. M.: Past changes in the vertical distribution of ozone - Part 3: Analysis and interpretation of trends, Atmos. Chem. Phys., 15, 9965-9982, doi:10.5194/acp-15-9965-2015, 2015.

Haynes, P.: Stratospheric dynamics, Annu. Rev. Fluid Mech., 37, 263-293, doi:10.1146/annurev.fluid.37.061903.175710, 2005.

Haynes, P., McIntyre, M., Shepherd, T., Marks, C., and Shine, K.: On the "Downward Control" of Extratropical Diabatic Circulations by Eddy-Induced Mean Zonal Forces, J. Atmos. Sci., 48, 651-680, doi:10.1175/15200469(1991)048<0651:OTCOED>2.0.CO;2, 1991.

Held, I. M. and Suarez, M. J.: A Proposal for the Intercomparison of the Dynamical Cores of Atmospheric General Circulation Models, B. Am. Meteorol. Soc., 75, 1825-1830, doi:10.1175/15200477(1994)075<1825:APFTIO>2.0.CO;2, 1994.

Hitchcock, P., Shepherd, T. G., and Yoden, S.: On the Approximation of Local and Linear Radiative Damping in the Middle Atmosphere, J. Atmos. Sci., 67, 2070-2085, doi:10.1175/2009JAS3286.1, 2010.

Hoskins, B. J. and Simmons, A. J.: A multi-layer spectral model and the semi-implicit method, Q. J. Roy. Meteor. Soc., 101, 637-655, doi:10.1002/qj.49710142918, 1975.

Kim, J., Grise, K. M., and Son, S.-W. W.: Thermal characteristics of the cold-point tropopause region in CMIP5 models, J. Geophys. Res.-Atmos., 118, 8827-8841, doi:10.1002/jgrd.50649, 2013.

Lambert, A., Read, W. G., Livesey, N. J., Santee, M. L., Manney, G. L., Froidevaux, L., Wu, D. L., Schwartz, M. J., Pumphrey,
H. C., Jimenez, C., Nedoluha, G. E., Cofield, R. E., Cuddy, D. T., Daffer, W. H., Drouin, B. J., Fuller, R. a., Jarnot, R. F., Knosp, B. W., Pickett, H. M., Perun, V. S., Snyder, W. V., Stek, P. C., Thurstans, R. P., Wagner, P. A., Waters, J. W., Jucks, K. W., Toon, G. C., Stachnik, R. A., Bernath, P. F., Boone, C. D., Walker, K. a., Urban, J., Murtagh, D., Elkins, J. W., and Atlas, E.: Validation of the Aura Microwave Limb Sounder middle atmosphere water vapor and nitrous oxide measurements, J. Geophys. Res.-Atmos., 112, 1-24, doi:10.1029/2007JD008724, 2007.

Logan, J. A.: An analysis of ozonesonde data for the troposphere: Recommendations for testing 3-D models and development of a gridded climatology for tropospheric ozone, J. Geophys. Res.Atmos., 104, 16115-16149, doi:10.1029/1998JD100096, 1999.

Maycock, A. C., Shine, K. P., and Joshi, M. M.: The temperature response to stratospheric water vapour changes, Q. J. Roy. Meteor. Soc., 137, 1070-1082, doi:10.1002/qj.822, 2011.

Maycock, A. C., Joshi, M. M., Shine, K. P., Davis, S. M., and Rosenlof, K. H.: The potential impact of changes in lower stratospheric water vapour on stratospheric temperatures over the past 30 years, Q. J. Roy. Meteor. Soc., 140, 2176-2185, doi:10.1002/qj.2287, 2014.

Ming, A., Hitchcock, P., and Haynes, P.: The Response of the Lower Stratosphere to Zonally Symmetric Thermal and Mechanical Forcing, J. Atmos. Sci., 73, 1903-1922, doi:10.1175/JAS-D15-0294.1, 2016.

Mlynczak, M. G., Mertens, C. J., Garcia, R. R., and Portmann, R. W.: A detailed evaluation of the stratospheric heat budget: 2 . Global radiation balance and diabatic circulations, J. Geophys. Res.-Atmos., 104, 6039-6066, doi:10.1029/1998JD200099, 1999.

Morcrette, J.-J.: Radiation and cloud radiative properties in the European Centre for Medium Range Weather Forecasts forecasting system, J. Geophys. Res.-Atmos., 96, 9121-9132, doi:10.1029/89JD01597, 1991.

Mote, P. W., Rosenlof, K. H., Mcintyre, E., Carr, E. S., Gille, J. C., Holton, R., Kinnersley, S., Pumphrey, H. C., Russell III, J. M., and Waters, J. W.: An atmospheric tape recorder: The imprint of tropical tropopause temperatures on stratospheric water vapor, J. Geophys. Res., 101, 3989-4006, 1996.

Plumb, R. A.: Zonally-symmetric Hough modes and meridional circulations in the middle atmosphere, J. Atmos. Sci., 39, 983-991, 1982.

Ramanathan, V. and Dickinson, R. E.: The Role of Stratospheric Ozone in the Zonal and Seasonal Radiative Energy Balance of the Earth-Troposphere System, J. Atmos. Sci., 36, 1084-1104, doi:10.1175/1520-0469(1979)036<1084:TROSOI>2.0.CO;2, 1979.

Randel, W. J. and Jensen, E. J.: Physical processes in the tropical tropopause layer and their roles in a changing climate, Nat. Geosci., 6, 169-176, doi:10.1038/ngeo1733, 2013.

Randel, W. J., Wu, F., Gettelman, A., Russell III, J. M., Zawodny, J. M., and Oltmans, S. J.: Seasonal variation of water vapor in the lower stratosphere observed in Halogen Occultation Experiment data, J. Geophys. Res., 106, 14313-14325, doi:10.1029/2001JD900048, 2001.

Randel, W. J., Garcia, R. R., and Wu, F.: Time-Dependent Upwelling in the Tropical Lower Stratosphere Estimated from the Zonal-Mean Momentum Budget, J. Atmos. Sci., 59, 2141-2152, 
doi:10.1175/1520-0469(2002)059<2141:TDUITT>2.0.CO;2, 2002.

Randel, W. J., Wu, F., and Rios, W.: Thermal variability of the tropical tropopause region derived from GPS/MET observations, J. Geophys. Res., 108, 1-12, doi:10.1029/2002JD002595, 2003.

Randel, W. J., Park, M., Wu, F., and Livesey, N.: A Large Annual Cycle in Ozone above the Tropical Tropopause Linked to the Brewer-Dobson Circulation, J. Atmos. Sci., 64, 4479-4488, doi:10.1175/2007JAS2409.1, 2007.

Reed, R. J. and Vlcek, C. L.: The Annual Temperature Variation in the Lower Tropical Stratosphere, J. Atmos. Sci., 26, 163-167, doi:10.1175/1520-0469(1969)026<0163:TATVIT>2.0.CO;2, 1969.

Seviour, W. J. M., Butchart, N., and Hardiman, S. C.: The BrewerDobson circulation inferred from ERA-Interim, Q. J. Roy. Meteor. Soc., 138, 878-888, doi:10.1002/qj.966, 2012.

Solomon, S., Rosenlof, K. H., Portmann, R. W., Daniel, J. S., Davis, S. M., Sanford, T. J., and Plattner, G.-K.: Contributions of stratospheric water vapor to decadal changes in the rate of global warming, Science, 327, 1219-1223, doi:10.1126/science.1182488, 2010.

Stolarski, R. S., Waugh, D. W., Wang, L., Oman, L. D., Douglass, A. R., and Newman, P. A.: Seasonal variation of ozone in the tropical lower stratosphere: Southern tropics are different from northern tropics, J. Geophys. Res.-Atmos., 119, 61966206, doi:10.1002/2013JD021294, 2014.
Tegtmeier, S., Hegglin, M. I., Anderson, J., Bourassa, A., Brohede, S., Degenstein, D., Froidevaux, L., Fuller, R., Funke, B., Gille, J., Jones, A., Kasai, Y., Krüger, K., Kyrölä, E., Lingenfelser, G., Lumpe, J., Nardi, B., Neu, J., Pendlebury, D., Remsberg, E., Rozanov, A., Smith, L., Toohey, M., Urban, J., Von Clarmann, T., Walker, K. A., and Wang, R. H. J.: SPARC Data Initiative: A comparison of ozone climatologies from international satellite limb sounders, J. Geophys. Res.-Atmos., 118, 12229-12247, doi:10.1002/2013JD019877, 2013.

Tummon, F., Hassler, B., Harris, N. R. P., Staehelin, J., Steinbrecht, W., Anderson, J., Bodeker, G. E., Bourassa, A., Davis, S. M., Degenstein, D., Frith, S. M., Froidevaux, L., Kyrölä, E., Laine, M., Long, C., Penckwitt, A. A., Sioris, C. E., Rosenlof, K. H., Roth, C., Wang, H.-J., and Wild, J.: Intercomparison of vertically resolved merged satellite ozone data sets: interannual variability and long-term trends, Atmos. Chem. Phys., 15, 3021-3043, doi:10.5194/acp-15-3021-2015, 2015.

Zhong, W. and Haigh, J. D.: Improved Broadband Emissivity Parameterization for Water Vapor Cooling Rate Calculations, J. Atmos. Sci., 52, 124-138, 1995. 